\title{
Perspectives on the future of manufacturing within the Industry 4.0 era
}

\begin{abstract}
The technological choices facing the manufacturing industry are vast and complex as the industry contemplates the increasing levels of digitization and automation in readiness for the modern competitive age. These changes broadly categorized as Industry 4.0, offer significant transformation challenges and opportunities, impacting a multitude of operational aspects of manufacturing organizations. As manufacturers seek to deliver increased levels of productivity and adaptation by innovating many aspects of their business and operational processes, significant challenges and barriers remain. The roadmap toward Industry 4.0 is complex and multifaceted, as manufacturers seek to transition toward new and emerging technologies, whilst retaining operational effectiveness and a sustainability focus. This study approaches many of these significant themes by presenting a critical evaluation of the core topics impacting the next generation of manufacturers, challenges and key barriers to implementation. These factors are further evaluated via the presentation of a new Industry 4.0 framework and alignment of I4.0 themes with the UN Sustainability Goals.
\end{abstract}

Keywords: Industry 4.0, Big Data, Internet of Things (IoT), Artificial Intelligence (AI), Sustainability. 


\section{Introduction}

The emergence of a new wave of disruptive technological innovation has impacted the manufacturing industry as consumer demands for mass-customization and increased levels of sustainability, drive operational effectiveness and flexibility to adaptation. These new concepts, technologies and processes set to transform the manufacturing landscape, have been collectively termed the fourth Industrial Revolution - namely Industry 4.0 (I4.0). The I4.0 concept originally stems from a German initiative led by the Federal Ministry of Education and Research in the context of their high-tech strategy 2020. The initiative set out to amalgamate manufacturing and technology via a formal standardization roadmap for I4.0 (DIN \& DKE 2018; Kagermann 2011; Lasi et al. 2014). Studies have associated I4.0 with a number of fundamental interrelated concepts and innovations aligned to technological as well as socioeconomic transformation of the manufacturing industry and factory of the future (Zhong et al. 2017; Liao et al. 2017).

The underlying principles associated with the I4.0 strategic initiative, are the use of Cyber Physical Systems (CPS) and related technologies to realize a highly flexible and digitally driven intelligent factory (Zhou and Zhou 2015). This requires constant connectivity, "human in the loop" capability and decentralized decision-making (Muhuri et al. 2019). Although studies have highlighted the evolving nature of I4.0 (Liao et al. 2017), the literature generally supports that I4.0 is built around a number of core concepts and digitally aligned technological initiatives:- Internet of Things (IoT), big data, cloud computing, smart manufacturing and the intelligent factory, adaptive manufacturing, Artificial Intelligence (AI) and automation via the use of CPS (Lu 2017; Rüßmann et al. 2015; Zhong et al. 2017). At its core, I4.0 relies on the seamless integration and implementation of these technologies and digital initiatives to transform manufacturing and deliver higher levels of efficiency and productivity (Ahuett-Garza \& Kurfess 2018; Lu 2017). 
The Swiss based - World Economic Forum (WEF) has analysed the impact of smart machines and greater levels of automation on organisation productivity. The WEF asserts that globally - 75 million jobs may be displaced by automation as early as 2022. However, the WEF asserts that 133 million new jobs will be created as a direct result of technological progress and requirements for additional skills and expertise (WEF 2018). Studies have highlighted the potential increases in production efficiency from I4.0 adoption, with estimates as high as $30 \%$ gains across the manufacturing sector (Zhou and Zhou, 2015). The integrated digital infrastructure associated with I4.0 is predicted to deliver - greater efficiencies, faster industrial processes, foster economic growth and dramatically alter the profile of the existing workforce (Rüßmann et al. 2015). Although this new technology driven wave of innovation is positioned as offering significant disruptive change to the manufacturing industry, numerous barriers exist for many sectors especially those within emerging economies (Cardoso et al. 2017; Frolov et al. 2018) and smaller scale manufacturers in the context of adaptation deficits when compared to larger enterprises (Mittal et al. 2018; Sommer 2015). The drive toward increased levels of flexibility and customization to support I4.0 transition, requires significant financial investment as well as CPS based connectivity and integration between systems (Fatorachian and Kazemi 2018). These factors highlight the potential challenges for organisations as the industry transitions to a more flexible and intelligent method of production via the use of IoT based digital systems and CPS technology.

The challenges surrounding sustainability are key factors for industry, as manufacturers strive for greater efficiencies and consumers increasingly view consumerism through the lens of reduced impact on the planet and its inhabitants. In their transition to the smart factory of the future, manufacturers are required to balance the economic realities of an I4.0 approach whilst achieving desired levels of sustainability throughout the product lifecycle (Varela et al. 2019; Yao et al. 2017; 
Zhang et al. 2018). Building in a more focussed sustainable manufacturing framework that creates value within the I4.0 model, is key to success within economic, social and environmental contexts (Braccini, \& Margherita 2018; Li et al. 2018).

The transition to I4.0 is complex and multifaceted. No prescriptive strategic roadmap exists to help organisations progress from traditional manufacturing processes along the road to I4.0 (Ghobakhloo, 2018). The industry as a whole exhibits varied levels of I4.0 maturity with specific developed economies such as Germany and Switzerland leading the way as they successfully transition their industrial infrastructure (Mittal et al. 2018; Müller et al. 2017). However, many manufacturers are facing substantial challenges not only in the context of their own organisations, but also with the supply chain as a whole as all these elements migrate to new ways of working (Schumacher et al. 2016). Less developed economies face significant challenges with demonstrably lower levels of I4.0 maturity and a reliance on a labour intensive model. Studies have highlighted the unrealistic expectation that manufacturers can transition to I4.0 from a low automation model without significant government and industry-wide investment and support (Braccini, \& Margherita 2018; Strandhagen et al. 2017; Tortorella \& Fettermann, 2018; Zhou et al. 2015). Manufacturers may be at various transition points along the I4.0 roadmap and maturity level. Recognising this as the industry wide reality can help to frame the specific sector requirements and transition path for many organisations (Mittal et al. 2018).

The wider literature has published extensively on I4.0 and its associated topics, focusing on many of the technological implications for the industry as a whole. Generally, business related research has tended to discuss specific I4.0 topics addressing key themes such as big data, IoT, intelligent manufacturing, $\mathrm{AI}$ and their impact on factories of the future. A number of studies have sought to pull together many of these numerous strands offering a review of the available literature 
(Kamble et al. 2018; Lu 2017; Muhuri et al. 2019). However, studies have generally tended to focus on the literature search output or concentrated on individual themes rather than offer a substantive discussion of the key topics, challenges for organisations and implication for theory and industrial practice. Additionally, the trajectory toward I4.0 and all its potential implications, is fast paced and evolving with no one size fits all solution, highlighting the complexities from the I4.0 transition perspective (Ghobakhloo 2018; Haeffner \& Panuwatwanich 2017; Lalic et al. 2017). Additional theoretical insight via a timely evaluation of the key topics through an up to date lens, can offer new contribution to literature. This study seeks to fill this gap with a review of the associated technological themes surrounding I4.0, exploration of the developing and emerging market perspective and an analysis of I4.0 from a sustainability context, specifically the United Nations (UN) Sustainable Development Goals (SDG). The study pulls many of these threads together with an analysis of applicable frameworks within the wider I4.0 related literature and the presentation of a new I4.0 transition framework.

The remainder of the paper is structured as follows: section 2) details the literature review where the methodology and the key I4.0 related themes are outlined. The key challenges facing organisations migrating toward I4.0 are presented in section 3) grouped from emerging markets, sustainability and transition perspectives. This section also includes the presentation and discussion of an adapted I4.0 operationalization framework. The paper is concluded within section 4).

\section{Literature Review}

The literature review is divided into a number of sections. The first describes the methodology used to source the relevant research; the second presents the results of the database search; the 
third details the main categories based on the literature review that are used to describe many of the key concepts surrounding I4.0 and manufacturing.

\subsection{Methodology}

This study aligns with the guidance outlined in Webster and Watson (2002) and Moher et al. (2009) in the context of conducting a structured and systematic approach to the literature review. The key stages are outlined in Figure 1 using an adapted version of the Moher et al. (2009) flow diagram.
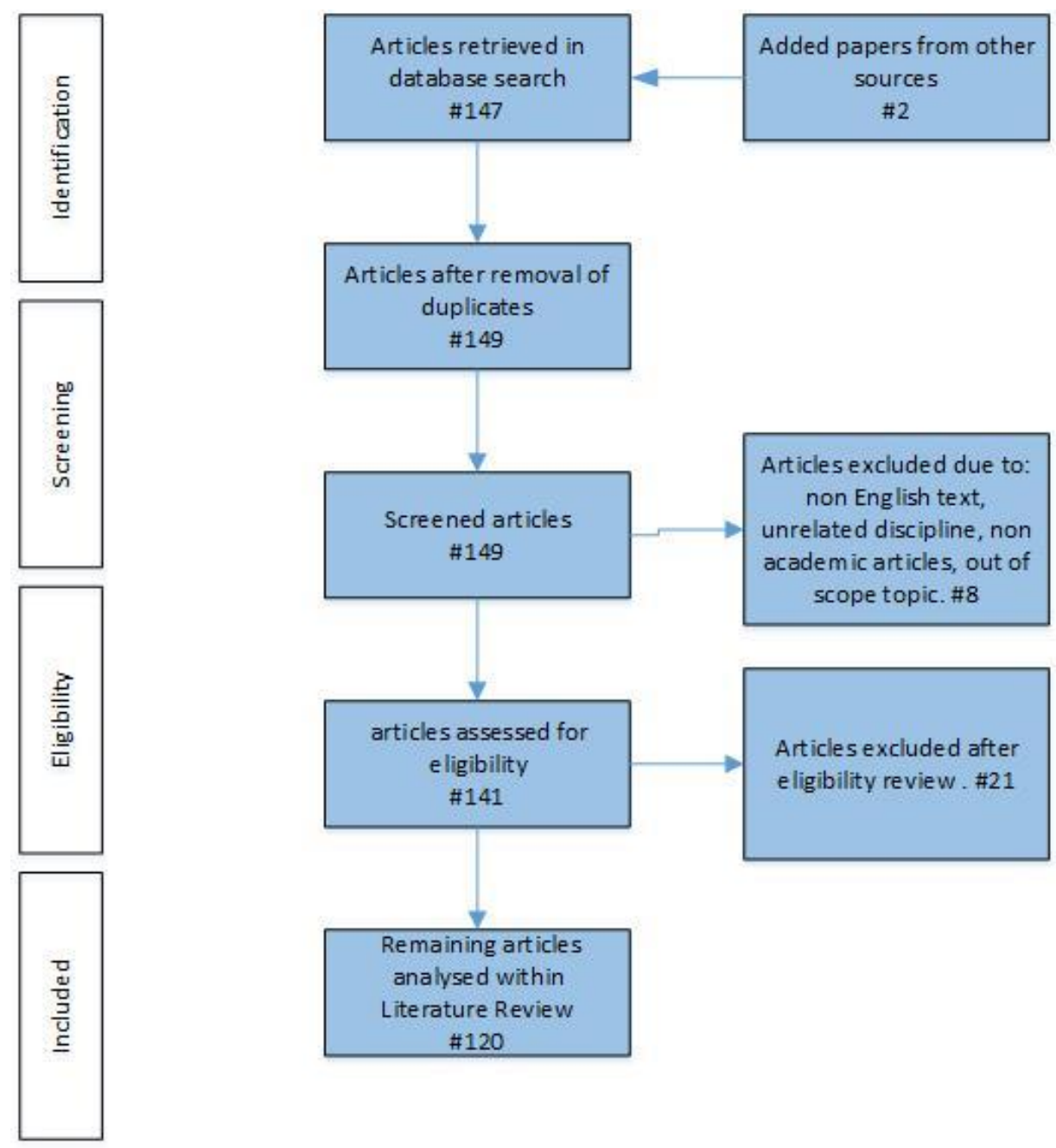
Figure 1: Literature review process (adapted from Moher et al. 2009)

The literature review searches were undertaken via Web of Science and Scopus databases as well as Google Scholar to return primarily chartered Association of Business Schools (ABS) related papers that fulfilled the search criteria. The searches undertaken were as follows: "Big Data" AND "Manufacturing”, “AI" AND "Manufacturing", "IoT” AND "Manufacturing”, "Big data" AND “Manufacturing”, "Sustainability” AND "Manufacturing”, "Industry 4.0” AND "Manufacturing”. No restrictions were placed on publishing year although the bulk of the results returned were 2015 or later, reflecting perhaps the fact that I4.0 is a relatively recent research area. This initial search yielded 147 separate results. No restrictions were placed on specific journals or ABS ranking. Additional known relevant studies where included from outside this initial search and added to the articles for the initial screening. Via a process of assessing eligibility and eliminating nonmanufacturing and unrelated papers, the result set was narrowed to 120 articles. Each of these individual papers were reviewed to ascertain emerging themes or patterns that would help categorise the result set across the full literature.

\subsection{I4.0 Themes}

The list of categorised articles are presented in table 1 . The selected themes were identified based on a review of each of the articles where the key relevant content for each study was captured in table form. No fixed view on theme groupings were initially developed, rather these were allowed to emerge as the review progressed. A number of draft theme titles were selected based on an assessment of the key topic areas of each of the main groupings of articles. These titles and descriptions were then appraised via a review within the research team to validate the constituent 
papers, selected title and narrative. Subsequent to the review, the chosen themes were validated and where articles were categorised incorrectly, these were moved to the relevant theme. Studies that addressed a number of topics across multiple themes are subsequently listed in each appropriate category. Additional relevant studies were added to the categorised list where the review highlighted valid and key article references not picked up in the initial search.

Table 1: I4.0 Themes

\begin{tabular}{|c|c|c|}
\hline I4.0 Theme & Theme Description & Study References \\
\hline $\begin{array}{l}\text { Flexible and additive } \\
\text { manufacturing } \\
\text { perspectives }\end{array}$ & $\begin{array}{l}\text { Implications for } \\
\text { manufacturers as demands } \\
\text { increase for customisation, } \\
\text { flexibility on batch sizes and } \\
\text { requirements for additive } \\
\text { manufacturing processes } \\
\text { with an increasing range of } \\
\text { materials. }\end{array}$ & $\begin{array}{l}\text { Ahuett-Garza \& Kurfess,(2018); Caputo et al. (2016); } \\
\text { Frank et al. (2019); Gao et al. (2015); Kusiak (1987); } \\
\text { Oesterreich \& Teuteberg (2016); Park \& Huh (2018); } \\
\text { Pikas et al. (2016); ); Renzi et al. (2014); Santos et al. } \\
\text { (2017); Sayar \& Er (2018); Szalavetz (2018); Theorin } \\
\text { et al. (2017); Vujosevic (1994); Wang \& Wang } \\
\text { (2016); Wang et al. (2018) }\end{array}$ \\
\hline $\begin{array}{l}\text { Intelligent } \\
\text { manufacturing } \\
\text { and smart factory of } \\
\text { the future }\end{array}$ & $\begin{array}{l}\text { Concepts relating to } \\
\text { utilising many of the } \\
\text { available new technologies } \\
\text { to organise and develop } \\
\text { production to meet the new } \\
\text { demands of I4.0. }\end{array}$ & $\begin{array}{l}\text { Ahuett-Garza \& Kurfess,(2018); Braccini \& } \\
\text { Margherita (2018); DIN \& DKE (2018); Du \& Yang } \\
\text { (2015); Fatorachian \& Kazemi (2018); Frank et al. } \\
\text { (2019); Fujino \& Konno (2016); Ismail et al. (2019); } \\
\text { Jonsson \& Svensson (2016); Kiel et al. (2017); Lalic } \\
\text { (2017); Lasi et al. (2014); Li et al. (2017); Mittal et al. } \\
\text { (2018); Nikolic et al. (2017); O’Donovan et al. (2015); } \\
\text { Qi \& Tao (2018); Shukla et al. (2018); Yao et al. } \\
\text { (2017); Zheng et al. (2018); Zhong et al. (2017a); } \\
\text { Zhong et al. (2017b) }\end{array}$ \\
\hline $\begin{array}{l}\text { AI and human in the } \\
\text { loop concepts }\end{array}$ & $\begin{array}{l}\text { Implications for future of } \\
\text { automation and potential } \\
\text { machine vs human } \\
\text { interaction in alignment } \\
\text { with manufacturing goals. }\end{array}$ & $\begin{array}{l}\text { DIN \& DKE (2018); Haeffner \& Panuwatwanich } \\
\text { (2017); Jain and Mosier (1992); Jonsson \& Svensson } \\
\text { (2016); Katz (2017); Kumar (2017); Kusiak (1987); } \\
\text { Lee et al. (2018); Lee (2002); Li (2018); Li et al. } \\
\text { (2017); Löffler \& Tschiesner (2013); Makridakis } \\
\text { (2018); Muhuri et al. (2019); Nikolic et al. (2017); } \\
\text { Wang et al. (2015); Wang \& Wang (2018); Yang et al. } \\
\text { (2017); Zhong et al. (2017a) }\end{array}$ \\
\hline
\end{tabular}




\begin{tabular}{|c|c|c|}
\hline $\begin{array}{l}\text { Big data and analytic } \\
\text { perspectives }\end{array}$ & $\begin{array}{l}\text { Underlying concepts and } \\
\text { complexities in the } \\
\text { processing of large } \\
\text { manufacturing datasets and } \\
\text { the analytical interpretation } \\
\text { of data. }\end{array}$ & $\begin{array}{l}\text { Auschitzky et al. (2014); Brock \& Khan (2017); } \\
\text { Chang \& Lin (2019); Chien et al. (2017); Contreras \& } \\
\text { Perez (2018); Cooley \& Petrusich (2013); Depeige \& } \\
\text { Doyencourt (2015); Gandomi \& Haider (2015); } \\
\text { Gunasekaran et al. (2018); Hang et al. (2014); Kumar } \\
\text { et al. (2016); LaCasse et al. (2018); Mousannif et al. } \\
\text { (2016); O'Donovan et al. (2015); Olshannikova et al. } \\
\text { (2015); Qi \& Tao (2018); Rymaszewska et al. (2017); } \\
\text { Santos et al. (2017); Shukla et al. (2018); Spanaki et } \\
\text { al. (2018); Wang \& Wang (2016); Yadegaridehkordi } \\
\text { et al. (2018); Zaki et al. (2017); Zheng et al. (2016); } \\
\text { Zhong et al. (2017a); Zhong et al. (2017b); Zhou et al. } \\
\text { (2015). }\end{array}$ \\
\hline $\begin{array}{l}\text { Impact of IoT, cloud } \\
\text { computing and } \\
\text { emerging } \\
\text { technologies }\end{array}$ & $\begin{array}{l}\text { IoT related factors and } \\
\text { criticality of this } \\
\text { technological concept as } \\
\text { part of the overall delivery } \\
\text { of } \mathrm{I} 4.0\end{array}$ & $\begin{array}{l}\text { Barenji et al. (2018); Birge (2018); Caputo et al. } \\
\text { (2016); Cheng et al. (2018); Contreras \& Perez (2018); } \\
\text { Fang et al. (2016); Jeschke et al. (2017); Jimenez et al. } \\
\text { (2019); Kiel et al. (2017); Ko et al. (2018); Kumar et } \\
\text { al. (2016); Liu \& Xu (2017); Li et al. (2018); Li et al. } \\
\text { (2017); Papakostas et al. (2016); Qin et al. (2016); } \\
\text { Rymaszewska et al. (2017); Sayar \& Er,(2018); } \\
\text { Shridhar (2019); Tu et al. (2018); Wang et al. (2015) }\end{array}$ \\
\hline $\begin{array}{l}\text { Sustainability factors } \\
\text { and impact on I } 4.0\end{array}$ & $\begin{array}{l}\text { Sustainability issues as } \\
\text { manufacturers progress } \\
\text { toward greater levels of } \\
\text { automation and how I4.0 } \\
\text { can be aligned with key } \\
\text { sustainability principles. }\end{array}$ & $\begin{array}{l}\text { Braccini \& Margherita (2018); Ferrera et al. (2017); } \\
\text { Ghafoorpoor Yazdi et al. (2018); Ko et al. (2018); Lasi } \\
\text { et al. (2014); Papadopoulos et al. (2017); Santos et al. } \\
\text { (2017); de Sousa Jabbour et al. (2018); Varela et al. } \\
\text { (2019); Zhang et al. (2018); Zhou et al. (2016) }\end{array}$ \\
\hline $\begin{array}{l}\text { I4.0 maturity and } \\
\text { roadmap }\end{array}$ & $\begin{array}{l}\begin{array}{l}\text { Trajectory of I4.0 and } \\
\text { implications }\end{array} \\
\text { manufacturers } \\
\text { on their I4.0 maturity levels. }\end{array}$ & $\begin{array}{l}\text { Almada-Lobo (2016); Cardoso et al. (2017); DIN \& } \\
\text { DKE (2018); Frolov et al. (2017); Gentner (2016); } \\
\text { Ghobakhloo (2018); Haeffner \& Panuwatwanich } \\
\text { (2017); Hauer et al. (2018); Jayaraman et al. (2018); } \\
\text { Kamble et al.(2018); Khan \& Turowski (2016); Li } \\
\text { (2018); Liao et al. (2017); Löffler \& Tschiesner } \\
\text { (2013); Mittal et al. (2018); Müller et al. (2017); } \\
\text { Papakostas et al. (2016); Pikas et al. (2016); Rüßmann } \\
\text { et al. (2015); Schumacher et al. (2016); Shridhar } \\
\text { (2019); Sommer (2015); Strandhagen et al. (2017); } \\
\text { Theorin et al. (2017); Zhou et al. (2015); Zúñiga et al. } \\
\text { (2017) }\end{array}$ \\
\hline $\begin{array}{l}\text { Process, efficiency } \\
\text { and productivity } \\
\text { perspectives }\end{array}$ & $\begin{array}{l}\text { Implications for efficiency } \\
\text { and productivity levels as a } \\
\text { direct result of } \mathrm{I} 4.0 \text { and }\end{array}$ & $\begin{array}{l}\text { Baines et al. (2017); Brettel et al. (2014); Buer et al. } \\
\text { (2018); Chien et al. (2017); Contreras \& Perez (2018); } \\
\text { Cooley \& Petrusich (2013); Cardoso et al. (2017); } \\
\text { Frolov et al. (2017); Lu (2017); Pereira \& Romero }\end{array}$ \\
\hline
\end{tabular}




\begin{tabular}{|l|l|l|}
\hline $\begin{array}{l}\text { intelligent manufacturing } \\
\text { concepts. }\end{array}$ & $\begin{array}{l}\text { (2017); Pikas et al. (2016); Reischauer (2018); } \\
\text { Rüßmann et al. (2015); Rymaszewska et al. (2017); } \\
\text { Sanders et al. (2016); Schumacher et al. (2016); } \\
\text { Szalavetz (2018); Venables (2016). }\end{array}$ \\
\hline
\end{tabular}

\subsection{Key Concepts and Themes aligned with I4.0}

A number of key concepts and emerging technologies can be associated with the transition to I4.0. Each of the key themes from table 1 form a critical component of the overall I4.0 proposition. Studies have addressed a number of these areas highlighting many of the enabling technologies and potential barriers to progress along the road to the next generation of manufacturing. Each of the themes are discussed below:

\subsubsection{Flexible and additive manufacturing perspectives}

Additive manufacturing (AM) has transformed the way that products are designed, manufactured and supplied to customers. Fully working products and components can be manufactured using flexible 3D printing and rapid prototyping technologies that construct objects using a material layering process (Oesterreich \& Teuteberg 2016). The technology allows complex product designs to be downloaded and constructed remotely via specialised automated AM technologies (Gao et al. 2015). Materials such as plastics, polymers, metals and concrete can be incorporated within the AM process. Products and components developed via AM techniques include: aircraft engine components, medical products (orthopaedics), automotive, consumer products, industrial tooling and small batch customised products (Additive Manufacturing 2019; Ahuett-Garza \& Kurfess 2018; BBC 2019). 
Studies have highlighted the disruptive influences from flexible approaches and AM within the overall I4.0 context (Caputo et al. 2016; Park \& Huh 2018; Szalavetz 2018). The contribution from AM processes is heavily dependent on connectivity via IoT aligned methods, enabling localised production with subsequent impact on supply chains (Park \& Huh 2018; Santos et al. 2017; Sayar \& Er 2018). The framework presented in Frank et al. (2019) identified the criticality of technology adoption and requirements for flexibility and adaptive techniques as key I4.0 drivers. The study highlights the impact of organisation size on I4.0 processes, articulating the role that AM can play as part of a staged I4.0 implementation model (Frank et al. 2019). Reconfigurable manufacturing systems are positioned as the solution to requirements for greater levels of manufacturing flexibility and mass customization as the industry responds to rapid changes in demand (Renzi et al. 2014; Romero and Molina 2011).

The requirements for greater levels of flexibility and customization within the I4.0 context is critical to the successful fulfilment of market demands for the smart factory of the future (Pikas et al. 2016; Burnes \& Towers 2016). The design of suitable flexible manufacturing systems and associated processes are complex and multifaceted (Kusiak 1987; Vujosevic (1994). Studies have highlighted the significant benefits of integrating cloud platforms and IoT enabled technologies to deliver flexible manufacturing capability (Wang \& Wang 2016; Wang et al. 2018). The implementation of suitable event driven, architectures and associated infrastructure that enable loose coupling and re-configurability are core I4.0 requirements for manufacturing flexibility (Theorin et al. 2017). 


\subsubsection{Intelligent manufacturing and smart factory of the future}

The terms intelligent manufacturing and smart factories have been posited in the literature with reference to I4.0 and manufacturing organisations ability to cater for the dynamics and fluctuations of the global market (Braccini \& Margherita 2018; Fatorachian \& Kazemi 2018; Fujino \& Konno 2016). Intelligent manufacturing enables organisations to achieve significant benefits through, flexible, smart and adaptable manufacturing processes via integrated systems and advanced technologies (Li et al. 2017; Shukla et al. 2018; Zhong et al. 2017a). These technologies may include IoT connectivity, utilisation of big data solutions, cloud computing and sensor based technologies within a CPS context. Smart factories will host the industrial processes required to efficiently manufacture products, optimise resource and react to dynamic customer requirements (Ahuett-Garza \& Kurfess 2018; DIN \& DKE 2018; Ismail et al. 2019; Zhong et al. 2017b). The conceptual framework defined within Zheng et al. (2018), highlights many of these key principles where the smart factory is described as the integration of the physical shop floor infrastructure and the virtual ICT world (Zheng et al. 2018). The driving forces and fundamental concepts for I4.0 outlined in Lasi et al. (2014), describe the smart factory equipped with sensors and autonomous systems using digital factory principles, application of technology (Lasi et al. 2014) and sociotechnical processes (Yao et al. 2017).

The trend toward increasing levels of mass customisation and shorter lead times to effectively respond to changing market demands, is a key tenant of the smart factory and intelligent manufacturing concepts (Jonsson \& Svensson 2016; Kiel et al. 2017; Lalic 2017). This agile orientated production philosophy where small batch sizes and operational reconfiguration is the norm, is forecast to be the new model for realising effective operations within the factory of the future (Jung et al. 2016; Rashid \& Tjahjono 2016). The challenges relating to factory 
reconfiguration can be aligned with smart factory efficiency, specifically with the closely coupled architecture of a number of I4.0 concepts. The research by O'Donovan et al. (2015) highlights these points in the context of data centric technologies such as IoT and big data, where the study discusses the criticality of machine uptime and availability of the smart manufacturing environment (O’Donovan et al. (2015). These themes are emphasised within Nikolic et al. (2017) where the challenges of intelligent manufacturing can be mitigated via smart systems with predictive capabilities (Nikolic et al. (2017) and machine learning (Yao et al. (2017).

The concept of the digital twin and its association with smart factories and intelligent manufacturing is an increasingly discussed topic within the literature. In scenarios where operational processes incorporating a digital twin are integrated with production infrastructure via CPS, manufacturers can drive greater efficiencies and productivity. The digital twin process entails the dynamic mapping of physical objects and virtual models in order to simulate design and production modelling (Grieves 2014; Tao \& Zhang 2017). This intelligent manufacturing approach negates premature, large-scale production re-configuration and facilitates rapid design change validation (Qi \& Tao (2018). Studies highlight the next generation of factories as adopting increasing elements of $\mathrm{AI}$ and automation incorporating collaborative human-machine processes (Yao et al. 2017). These concepts can be implemented within a complex manufacturing environment, where machine-learning systems can be integrated with human knowledge for key production tasks ( $\mathrm{Du} \&$ Yang 2015; Zhong et al. 2017a). The application of intelligent manufacturing techniques and processes are fundamental to the overall I4.0 concept however, in practice this transition can be complex and challenging (Mittal et al. 2018). The research outlined in Frank et al. (2019) highlights these issues succinctly in the context of adoption of "front end technologies" where smart manufacturing is central to the overall process. The study argues that 
the low levels of adoption of associated and integrated technologies such as big data and analytics, act as barriers in the transition toward smart manufacturing and alignment with I4.0 (Frank et al. 2019).

\subsubsection{AI and human in the loop concepts}

For decades researchers have explored the potential of AI to replace humans within the factory toward greater levels of decentralized decision making via intelligent automation and to tackle many of the unique challenges within modern production (Kusiak 1987; Lee et al. 2018; Muhuri

et al. 2019). AI concepts are likely to play an ever increasing role within an integrated I4.0 infrastructure as ever more production processes are automated (Lee 2002; Löffler \& Tschiesner 2013). AI technology will enable manufacturers to extend beyond simple automation, where machines can learn and improve autonomously using AI decision making algorithms (Yang et al. 2017). The addition of AI driven processes means that supply chain and production processes can be monitored and controlled in real time with greater levels of efficiency and productivity as part of an AI centric ecosystem (Jain and Mosier 1992; Lee et al. 2018; Zhong et al. 2017a). Studies have highlighted new manufacturing models and frameworks where the smart factory, AI technologies and autonomous sensing are integrated within an intelligent manufacturing infrastructure and ecosystem. The model presented in Li et al. (2017) utilised an intelligent manufacturing system architecture and manufacturing technology system via the integration of AI and related product technology ( $\mathrm{Li}$ et al. 2017). The Predictive Manufacturing System (PMS) model presented in Nikolic et al. (2017) highlights how AI methods can be used in a predictive context for flexible and intelligent manufacturing. 
The probabilistic analysis of the economic impact of AI and automation has been assessed by the Swiss based WEF where they predict that $20 \%$ of existing UK jobs will be displaced by AI and related technologies. This figure is greater in emerging economies such as China, where the level rises to $26 \%$, due to the greater scope for disruptive technological change within the manufacturing sector. AI and related technologies will drive innovation and economic growth creating of 133 million new jobs globally by 2022 and contributing to $20 \%$ of GDP in China alone by 2030 (WEF 2018). Although some aspects of the literature reference the replacement of human expertise (Kumar (2017) with AI based technology, a more pragmatic and realistic enhancementcentric approach seems to be emerging. The literature has recognised the potential fallibility and realistic limits of replacing all human workers with AI driven machines as part of an infinite drive to automation (Katz 2017). The I4.0 German Standardization Roadmap highlights the fact that humans will continue to play a significant role within the manufacturing environment but are likely to focus on design, maintenance and process related tasks to ensure long-term efficient and flexible production. This key principal asserts the rational of support, not replacement of human decision making (DIN \& DKE 2018). These points are emphasised within other aspects of the I4.0 based literature where CPS, automation and use of AI are discussed in the context of humans in the loop (Jonsson \& Svensson 2016; Makridakis 2018) or human - robot collaboration (Wang et al. 2015; Wang \& Wang 2018). The study by Haeffner \& Panuwatwanich (2017) posits the scenario of factory workers of the future, closely cooperating with AI based machines to solve problems. Within a fully operational I4.0 scenario robots and other intelligent devices, could become socially integrated within the production process even acting as co-workers for specific tasks (Haeffner \& Panuwatwanich 2017). 


\subsubsection{Big data and analytic perspectives}

The emergence of I4.0, its associated technologies and interconnected CPS infrastructure, has created a number of big data challenges and opportunities for manufacturers to generate new knowledge (Contreras \& Perez (2018). Within the automated age, data from production equipment, IoT connected networks, maintenance tools and supply chain status, needs to be formally managed and processed to enable key decision making. The I4.0 based smart factory of the future is likely to rely on significant real time and historical data generated from sensors within the manufacturing environment as machines monitor and control ever more aspects of production (Marr 2015). This concept of increasing levels of manufacturing intelligence extends this use of real time sensor based data, where manufacturing processes are optimised to sustain performance, improve productivity and influence big data adoption (Cooley \& Petrusich 2013; Yadegaridehkordi et al. 2018).

Big Data Analytics (BDA) facilitates the methodical and structured analysis of large data sets, often contextualised in terms of: volume, velocity, variety, veracity and value adding. BDA has the potential to transform and advance manufacturing and service systems offering value extraction and creative processing of heterogeneous data (Shukla et al. 2018; Spanaki et al. 2018; Wang \& Wang 2016). BDA can include the technologies and techniques that manufacturers can adopt to analyse large scale, complex data from a multitude of sources and applications (Brock \& Khan 2017; Chang \& Lin 2019). Within many manufacturing environments, the sheer scale and complexity of these large, unstructured and multi-dimensional datasets, necessitates utilising specific data mining and BDA software to process the production derived data (Zhong et al. 2017a; Kumar et al. 2016). Unstructured data forms approximately $95 \%$ of big data infrastructure, highlighting the complexity and requirements for sophisticated methods and associated software 
(Gandomi \& Haider 2015; LaCasse et al. 2018). The advent of new tools and processes for big data, allows analysts to efficiently access historical statistics in conjunction with real-time shop floor data, to develop advanced insights and drive critical decision-making (Auschitzky et al. 2014; Chien et al. 2017; Gunasekaran et al. 2018). BDA can be extended along the supply chain to deliver richer and more informed analysis, optimise customer value and drive efficiencies (Hang et al. 2014; Li et al. 2016).

Studies have posited the benefits of leveraging BDA and knowledge management practices within a predictive context toward greater levels of manufacturing intelligence and redistributed manufacturing insight (O’Donovan et al. 2015; Zaki et al. 2017). Significant advantage can be gained from the multi-dimensional elements of production data to help identify patterns and trends to aid manufacturers and their production schedules (Depeige \& Doyencourt 2015). The research by Qi \& Tao (2018) highlights the many benefits of access to big data where networked machines and smart devices can be optimised to negate defects and root causes of potential future breakdowns (Qi \& Tao 2018). The proposed roadmap outlined in Mousannif et al. (2016) highlights the role played by BDA within organisations and subsequent value of a systematic methodology in its implementation and return on investment (ROI). The framework proposed within Rymaszewska et al. (2017), positions the benefits of an IoT and big data approach via servitisation in the context of increased manufacturing productivity and value creation using analytics. This theme of value creation utilising big data is explored in Santos et al. (2017) where the study proposes a BDA architecture to enhance sustainable innovation within smart factories (Santos et al. 2017).

Data visualisation methods and tools play a key part in the ability of organisations to make sense of their big data structures. Greater levels of understanding and interpretation can be gained from 
the data where factors relating to human perception and cognition are taken into account (Olshannikova et al. 2015). The processing and synthesis of the multitude of heterogeneous data types within big data architectures is complex. Extracting value from big data via appropriate and scalable visualisation tools is a key and often expensive challenge, but also critical for organisations as volumes increase and new data types emerge (Zheng et al. 2016; Zhong et al. 2017b).

\subsubsection{Impact of IoT, cloud computing and emerging technologies}

The combination of IoT and cloud based technologies has the potential to transform manufacturing within the I4.0 era as this advanced connectivity to machines, devices, sensors and services delivers new value to manufacturers and the wider supply chain (Birge 2018; Caputo et al. 2016; Fang et al. 2016). The challenge within manufacturing is the integration within an effective IoT infrastructure such that all levels of production can communicate effectively (Wang et al. 2015). Studies have highlighted that $71 \%$ of manufacturers have either invested in, or plan to invest in IoT (Papakostas et al. 2016). IoT and cloud computing offer practical solutions to a number of manufacturing problems and service orientated barriers (Kumar et al. 2016; Liu \& Xu 2017). The modern efficient smart factory is likely to utilise an IoT based infrastructure to connect sensorbased technology within a digitally enabled CPS architecture to provide valuable real time data and statistics (Jeschke et al. 2017; Marr 2015). The IoT and cloud computing are essential components of intelligent manufacturing where BDA, AI concepts and adaptive production approaches can facilitate new business models and improved levels of productivity and efficiency (Kiel et al. 2017; Li et al. 2017; Qin et al. 2016). 
The advent of cloud computing and IoT has facilitated the emergence of cloud based manufacturing models where manufacturing as a service has begun to drive change within the intelligent factory (Barenji et al. 2018; Cheng et al. 2018; Helo \& Hao 2017). Service based approaches have begun to received attention within the I4.0 literature where the combination of CPS, IoT and associated networked sensor based technologies can address many manufacturing, logistics and supply chain issues. This servitisation perspective can position IoT based solutions to shorten product lifecycles and adapt to changing customer demands (Rymaszewska et al. 2017; Sayar \& Er 2018). The use of IoT based technologies has the potential to offer significant levels of improvements to productivity and efficiency when adopting a value chain perspective using: big data, supply chain, CPS security, monitoring and control (Contreras \& Perez 2018; Shridhar 2019).

The literature has discussed the application of blockchain technology within the supply chain and I4.0 context and its potential to offer considerable benefits to manufacturers. Many attributes of this emerging technology, in particular: immutability, enhanced security, decentralised distributed ledger and smart contract capability could positively impact manufacturing processes and supply chain models (Barenji et al. 2018; Ko et al. 2018). The smart contract aspect of blockchain technology has received considerable attention within the literature as researchers apply these concepts to real-world supply chain problems. The studies by Jimenez et al. (2019) and Li et al. (2018) highlight the potential for blockchain within the supply chain context where the concepts of open manufacturing and secure tracking of goods drive changes to industrial processes. Supply chain solutions utilising IoT information architectures such as the EPCglobal Network and RFID technologies can effectively offer real time product tracking data from factory to consumer using IoT and sensor technologies (Tu et al. 2018). 


\subsubsection{Sustainability factors and impact on I4.0}

Although the literature has explored many of the technological factors surrounding I4.0 and the smart factory of the future, studies have emerged that highlight a number of sustainability factors within the environmental and economic context in the new intelligent factory era (de Sousa Jabbour et al. 2018). Smart factories using IoT and sensor technology within production have the potential to address many aspects of sustainability through improved green supply chains and effective inventory management (Ben-Daya et al. 2017; Genovese et al. 2014). Empirical studies have analysed the relations between sustainability and I4.0 concluding that dependencies exists between the two concepts (Varela et al. 2019). The research by Braccini \& Margherita (2018) explores the impact of I4.0 adoption within manufacturing organisations in alignment with the sustainability dimensions of economic, environmental and social factors (triple bottom line). The study highlights the complexities inherent in balancing the environmental and economic sustainability factors as manufacturers transition toward I4.0 (Braccini \& Margherita 2018). The drive toward greater levels of digital and sustainability focussed transformation via I4.0 related technologies such as big data analytics, requires an understanding of key stakeholder interactions and interrelations where these elements can lead to knowledge, innovation, and value creation (Pappas et al. 2018). The potential economic and ecological increases in efficiency due to I4.0, require a sustained intensive focus on sustainability in all its forms (Lasi et al. 2014; Santos et al. 2017). The underlying technologies inherent within I4.0, offer significant opportunities via sensors and BDA tools to manage resources, support waste reduction initiatives and lessen environmental impact, as manufacturers adopt more efficient and adaptive approaches (Ferrera et al. 2017; Papadopoulos et al. 2017). BDA and IoT offer the potential for greater levels of sustainability 
where improvements in sensor technologies within harsh production environments can help to reduce energy consumption and improve efficiency (Zhang et al. 2018; Zhou et al. 2016).

The guidance published by the Organization for Economic Cooperation and Development (OECD) for sustainable manufacturing, sets out a number of steps under the overall categories of: Preparation, Measurement and Improvement. The OECD rules highlights the criticality of identifying sustainable objectives, driving continuous improvement and evaluating the factors surrounding: recyclability, use of hazardous materials and energy consumption (OECD 2014). The evaluation of operation Overall Equipment Effectiveness (OEE) presented in Ghafoorpoor Yazdi et al (2018), analyses the dichotomy of minimising operational risk whilst maximising the opportunities to improve processes in alignment with sustainable manufacturing principles within the I4.0 environment. The study posited the potential benefits to manufacturers in the balancing of OEE within the OECD framework (Ghafoorpoor Yazdi et al 2018).

The emergence of blockchain technology and its potential disruption within the manufacturing and supply chain industries, presents opportunities for greater levels of sustainability within the overall I4.0 vision of the future. The immutability and smart contract capability of blockchain technology, allows the provenance and integrity of products to be monitored more effectively. These factors contribute to reducing verification costs and provision of real time status information on the quality of materials throughout the supply chain (Ko et al. 2018). The disintermediation attributes of blockchain can directly contribute to manufacturing sustainability by effectively reducing complexity, improving efficiency with less waste via the streamlining of the supply chain (Hughes et al. 2019). 


\subsubsection{I4.0 maturity and roadmap}

The path to I4.0 capability is complex, with manufacturers exhibiting various states of readiness depending on organisation size and perception of funding levels (Sommer 2015). The standardization roadmap depicted within DIN \& DKE (2018) highlights the technological considerations as well as many of the automation, human in the loop and information security factors (DIN \& DKE 2018). Studies have highlighted the reality that organisations are at various maturity levels and technological investment trajectory as they migrate toward full I4.0 maturity (Jayaraman et al. 2018; Löffler \& Tschiesner 2013; Mittal et al. 2018). The direction of I4.0 technology adoption and transition toward greater levels of automation, could lead to a disrupted manufacturing industry where adaptive decentralised and interconnected production facilities become the established model (Almada-Lobo 2016; Rüßmann et al. 2015). In reality progress toward I4.0 and greater levels of efficiency, is likely to be at the individual manufacturer and not sector level or at the level of a complete supply chain (Schumacher et al. 2016). Progress along the I4.0 roadmap is likely to be country/sector specific where developed markets such as Germany and the US leading the way, whilst developing markets within countries such as India and Brazil require significant investment in technology and associated infrastructure (Cardoso et al. 2017; Frolov et al. 2017; Gentner 2016). The Chinese government "Made in China 2025" initiative is driving change toward greater levels of I4.0 maturity with advances reliant on the relationship between technological entrepreneurship and socio-economic changes (Li 2018; Liao et al. 2017; Pikas et al. 2016). The development of China's manufacturing is diversified across the country and the transition to I4.0 requires significant innovation as well as investment to build China's version of I4.0 in order to compete on the global stage (Zhou et al. 2015). Similarly, the "Make in India" initiative has delivered significant regional technological investment and smarter, IoT 
focussed infrastructure, although criticised for its poor outcomes in specific areas (Shridhar 2019). Researchers have analysed many of the I4.0 transition complexities highlighting that no single "one size fits all" roadmap exists to suit all industries (Strandhagen et al. 2017). The study by Ghobakhloo (2018) emphasises this point highlighting the criticality of developing an I4.0 roadmap based on the organisations core competencies and capabilities, taking into account priorities and financial considerations (Ghobakhloo 2018).

The path to I4.0 is centred on organisation change not just in the technological sense but also change that is likely to impact the daily lives of the workforce and wider stakeholders. The adoption of I4.0 is likely to require significant restructuring, impacting all levels of the organisation. Studies have highlighted the challenges in the context of corporate communications and the criticality of aligning messages with the overall organisation identity and stakeholder profile (Hauer et al. 2018). Manufacturers transitioning to I4.0 with greater levels of automation and adaptations to existing business models are likely to necessitate changes in workforce skills and expertise (Khan \& Turowski 2016). Many existing job roles may be redundant within a matured I4.0 model however, new skills and multidisciplinary expertise will be required to support manufacturers in the design and skilled support of the smart factory (Haeffner \& Panuwatwanich 2017; Papakostas et al. 2016).

The literature has analysed the key strategic decisions and many barriers to I4.0 adoption within industry, reflecting the significant challenges faced by manufacturers. The study by Müller et al. (2017) assessed the strategic factors surrounding the impact of I4.0 in the context of reshoring manufacturing capacity in Germany, highlighting the case for bringing production back to the country. Manufacturers exhibit reluctance to implement many of the new I4.0 related technologies due to: unclear benefits, large required investment and lack of clear implementation details 
(Theorin et al. 2017). The research by Kamble et al. (2018) analysed many of the barriers hindering I4.0 adoption within emerging markets, identifying many of the key interrelationships between the factors. The study highlighted the significant influence of the factors: high implementation cost and lack of clear comprehension about IoT benefits, on other I4.0 interconnected barriers (Kamble

et al. 2018). The sheer scale of required socio-technological change can be a significant barrier to many organisations embarking on a path toward I4.0 (Zúñiga et al. 2017). Manufacturers with a clear plan and defined ROI focussed business case are more likely to realise benefits and successful outcomes.

\subsubsection{Process, efficiency and productivity perspectives}

The key drivers for manufacturers to transition to I4.0 are related to reduced operating costs, productivity and efficiency gains underpinned by ROI focussed pragmatism (Buer et al. 2018; Cardoso et al. 2017). I4.0 has the potential to accelerate the ability of manufacturers to achieve new levels of operational effectiveness, efficiencies and corresponding impact on productivity and performance (Contreras \& Perez 2018; Lu 2017; Schumacher et al. 2016; Venables 2016). I4.0 is likely to engender the creation of new business models, impact the full product lifecycle, improve end to end processes and increase manufacturing competitiveness (Maddern et al. 2014; Pereira \& Romero 2017). To drive the desired increases in productivity associated with I4.0, manufacturing organisations will need to: communicate effectively, focus on core competencies and transition from offering superior products, to offering superior manufacturing capability (Brettel et al. 2014). The value driven shift to servitisation orientated business models referenced in a number of studies (Baines et al. 2017; Rymaszewska et al. 2017) highlights an I4.0 focussed value and efficiency 
perspective based on core manufacturing competencies and collaboration (Shamsuzzoha et al. 2016).

The transition from low technology labour intensive industries to greater levels of automation in alignment with the I4.0 model, requires significant investment in technology and infrastructure. The dilemma for manufacturers as to whether they can commit to Industry 4.0 is a consideration of the cost vs perceived benefits (Sanders et al. 2016). Within the emerging markets context, new business models, significant changes in processes and the drive for improved levels of productivity are likely to focus efforts toward an I4.0 focussed agenda (Pikas et al. 2016). The studies by Frolov et al. (2017) and Pikas et al. (2016) discussed many of these factors within the Russian and Chinese context respectively, highlighting the realities of poor efficiency, low productivity and requirement for significant industry wide investment I4.0 (Frolov et al. 2017). For many of these sectors, I4.0 is not a company specific initiative focussed on efficiency or productivity but is in effect a policydriven discourse focussed on innovation in manufacturing encompassing business, academia, and politics (Reischauer 2018).

I4.0 will make it possible to gather valuable data and develop analytics across the network supporting decision making and optimising performance of the manufacturing process (Chien et al. 2017; Cooley \& Petrusich 2013). This will enable faster, more flexible, highly efficient processes development to reduce the costs of production (Szalavetz (2018). These factors will increase productivity, engender industrial and economic growth, change the required workforce skillset and ultimately impact the competitiveness of companies and entire regions (Rüßmann et al. 2015). 


\section{I4.0 Challenges within identified themes}

This section pulls together a number of common threads from the I4.0 related themes extending some of the main topics for further discussion in the form of significant challenges. The three key challenges outlined are: 1) Emerging markets impact; 2) Aligning I4.0 in context of UN SDGs; 3) Transitioning to I4.0. Elements of these three challenges are inherent within many of the themes outlined in the previous section and each represent potential hurdles for organisations as they develop their I4.0 roadmaps. As shown in figure 2, we highlight the interconnectivity aspects of these challenges in relation to the overall I4.0 themes and the criticality for organisations to better understand the complexities within these areas. 


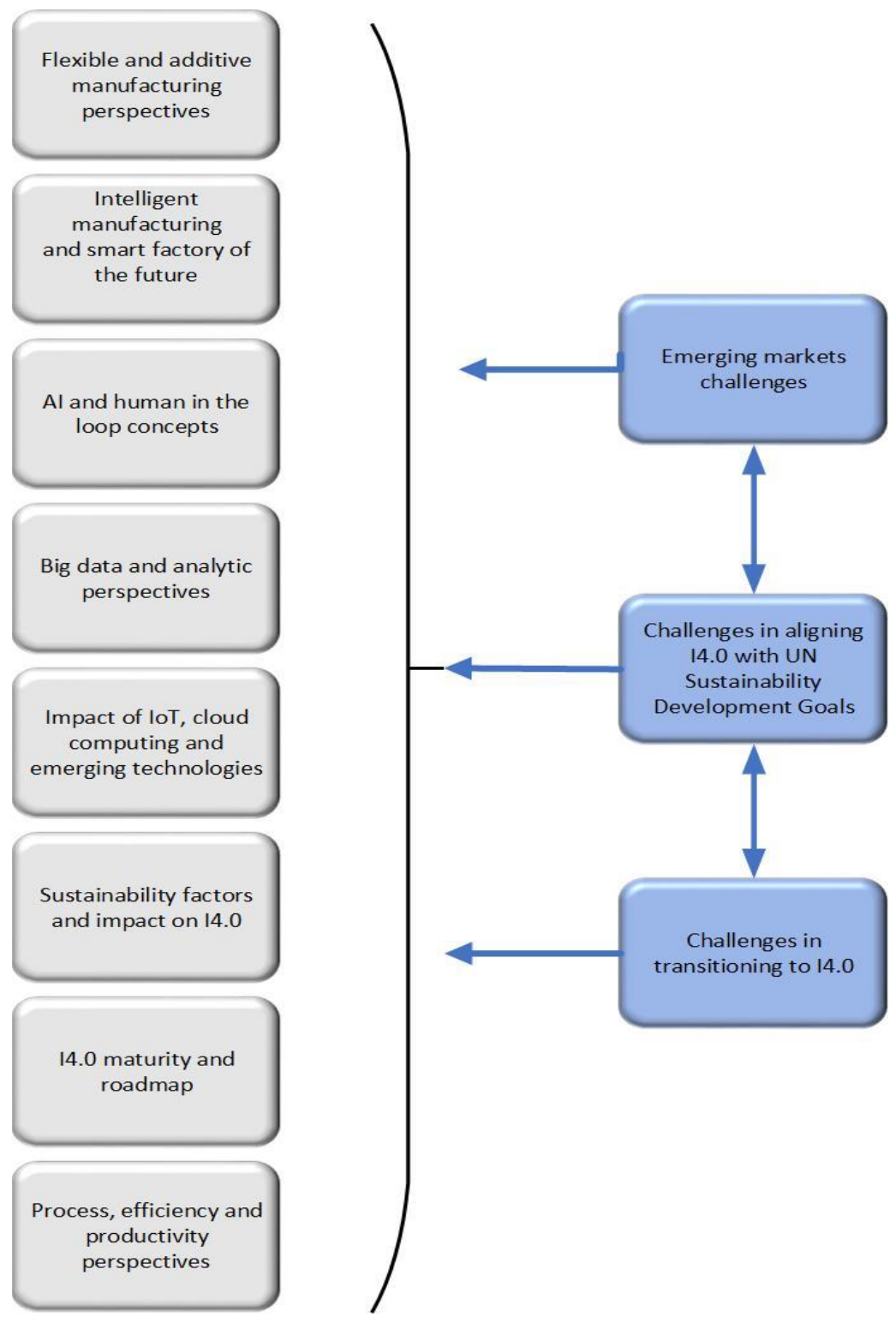

Figure 2: I4.0 Challenges

\subsection{Emerging markets challenges}

The literature has outlined the complexities and varied landscape of I4.0 maturity inherent within the manufacturing sector. The gap between the developed and emerging markets is clearly exposed 
for I4.0 related industries, where developed industrial sectors such as the US, Germany and many parts of the EU exhibit higher levels of I4.0 maturity than the majority of the sectors within developing markets (Haeffner \& Panuwatwanich 2017). Version three of the I4.0 standardisation roadmap outlined in DIN \& DKE (2018) highlights the level of maturity within Germany and the institutional support to drive change. Switzerland is defined as one of the leading counties in transitioning to I4.0, where Swiss industry is positioned as heading the global competitive index ahead of Singapore, the US and Germany (Genter 2016). Other developed manufacturing markets such as Japan have significant established digital based industrial infrastructure well placed for further automation and full migration to I4.0 (Fujino \& Konno 2016). The strategic approach from many of the developed markets outlines the commitment and investment necessary to transform industry to take advantage of the key technological changes within I4.0.

In stark contrast the emerging markets perspective is mixed with many countries still uncertain about the overall strategic direction and government commitment. Countries such as China have developed national initiatives with institutional support and commitment to technological change, whilst other less developed sectors such as Russia, India and many other Asian countries, are still reliant on significant labour intensive manufacturing processes. The "Made in China 2025" initiative seeks to transform the manufacturing capability of China from a low cost mass production sector to a strategic focus that builds a trajectory toward "designed in China" and "innovated in China" (Li 2018; Li et al. 2017). Studies have highlighted the significant technological investment and associated infrastructural change within China's manufacturing industry, positioned to leverage the economic might of the country and dominance within global trade (Pikas et al. 2016). China is becoming a more innovative and sophisticated manufacturer of goods and services with 1.38 million patent application in 2018 (40\% of the global total), the 
highest number of any country (WIPO 2018). Studies have identified the tremendous industrial potential of the Indian economy and institutional support for utilising technology to transform manufacturing (Haeffner \& Panuwatwanich 2017; Jayaraman et al. 2018). The "Make in India" initiative established in 2014 has prioritised the upgrading of the country's infrastructure, supported innovation, skills and training across 25 sectors within the Indian economy. Although criticised for its lack of significant industrial change, the initiative has attracted major investment from Huawei and Samsung (Shridhar 2019). The concept of I4.0 is gaining increased traction within Russia where government schemes such as the national technology initiative - TechNet have earmarked key industrial sectors as "markets of the future", requiring advanced manufacturing capability (Frolov et al. 2017). The Russian manufacturing sector requires significant investment and modernisation to align with many of the key themes within I4.0. The TechNet roadmap seeks to drive this change to provide technological support for establishing the smart factory within the Russian manufacturing sector (Frolov et al. 2017).

The economic impact of I 4.0 within many emerging markets is likely to be stark, as the drive to higher levels of automation has the potential to disenfranchise large sectors of the population that perhaps lack the re-education and retraining opportunities necessary to redeploy workers to new roles. Workers in some Asian sectors could be hardest hit by I4.0 as unemployment in countries such as China and India could significantly increase due to higher automation, factory resettlements and fewer opportunities to develop some of the necessary skills required for smart factories (Haeffner \& Panuwatwanich 2017). The study by Kamble et al. (2018) analysed many of these factors from the Indian perspective highlighting the criticality of impacts due to: employment disruption, high implementation cost, organisational and process changes and the need for enhanced skills. Governments have a significant role to play in the alignment of strategic aims 
with the necessary investment and policy directives to effect managed change. However, as highlighted in Shridhar (2019), unless government initiatives develop the required policies and skilled workers needed for the transition to I4.0, outcomes are uncertain.

\subsection{Challenges in aligning I4.0 in context of UN Sustainability Development Goals}

The increased levels of automation and efficiencies afforded by I4.0 technologies and associated processes, can facilitate the reduction of waste as organisations adopt smart manufacturing techniques and more efficient supply chains (Cooley \& Petrusich 2013; Ko et al. 2018). The increased levels of integration across the supply chain network with environmentally friendly practices built into manufacturing processes using an IoT focussed infrastructure, is likely to yield greater levels of waste reduction and improved sustainable outcomes (Ferrera et al. 2017; Ghafoorpoor et al. 2018; Ko et al. 2018; Sanders et al. 2016). The research undertaken by de Sousa Jabbour et al. (2018) illustrates these points, positing the unique potential of I4.0 technologies to play a significant role within the development of environmentally sustainable manufacturing.

The Sustainability Development Goals were developed by the UN in 2015 as part of its vision for the future. The goals were presented as a shared agenda and blueprint for peace and prosperity for the planet and population. The UN has developed 17 SDGs in total that highlight many of the key themes relating to ending poverty, improve health and education, focus on climate change, reduce inequality and develop sustainable economic growth (UN 2019). Previous studies have incorporated the UN SDG's within their research aligning some of the UN goals specifically with the directions or outcomes of the study. The study by Ismagilova et al. (2019), presented the UN SDGs in the context of future impact of Smart Cities and its citizens. The Hughes et al. (2019) study incorporated the UN SDGs from the perspective of blockchain technology and how this 
emerging technology could be aligned with the creation of business and social value (Hughes et al. 2019). This study has reviewed each of the UN SDGs from the perspective of potential alignment with I4.0 and its major themes. Based on these key comparisons, Table 2 details each of the SDGs and how specific elements of I4.0 can align with each goal.

Table 2: UN sustainable development goals vs I4.0 and emerging technologies

\begin{tabular}{|c|c|}
\hline UN SDGs & I4.0 and SDG alignment \\
\hline No poverty & \multirow[b]{3}{*}{$\begin{array}{l}\text { The increasing levels of efficiency and productivity inherent within } \\
\text { manufacturing organisations and supply chains that transition toward } \\
\text { I4.0 have the potential to directly impact human health and well- being. } \\
\text { Many emerging economies rely significantly on poorly skilled, low } \\
\text { paid manual processes within the manufacturing sector. The } \\
\text { emergence of I4.0 and the resulting increased levels of automation, } \\
\text { whilst eliminating many repetitive manufacturing jobs, will create } \\
\text { numerous more highly skilled and higher paid roles as organisations } \\
\text { become more efficient. However, in the emerging market context, } \\
\text { these outcomes are dependent on government as well as industry } \\
\text { investment in re-education and retraining to support the transition. } \\
\text { Consumers are likely to directly benefit from I4.0 related technologies } \\
\text { such as adaptive manufacturing and use of IoT, where communities } \\
\text { can gain the benefits of lower cost, greater efficiencies and } \\
\text { decentralised processes. }\end{array}$} \\
\hline Zero hunger & \\
\hline Good health and well-being & \\
\hline Quality education & \multirow{3}{*}{$\begin{array}{l}\text { The transition toward I4.0 and smart manufacturing requires new } \\
\text { expertise and gender neutral skills to design and support the } \\
\text { technologically focussed smart factory of the future. Newly created } \\
\text { jobs will require dedicated quality education and training to effectively } \\
\text { support the desired high levels of expertise and necessary skills. These } \\
\text { new skills and expertise are less likely to be focussed on gender } \\
\text { stereotypes as industry transitions to a less manually skilled workforce. }\end{array}$} \\
\hline Gender equality & \\
\hline Reduced inequalities & \\
\hline Clean water and sanitation & \multirow[b]{2}{*}{$\begin{array}{l}\text { The drive toward I } 4.0 \text { and the smart factory where adaptive and } \\
\text { flexible manufacturing can develop products in small batch sizes can } \\
\text { support these SDGs. Components directly related to clean water and } \\
\text { sanitation can be designed anywhere in the world, manufactured "in } \\
\text { country" and shipped to the point of need relatively quickly. Increasing } \\
\text { efficiencies and the drive toward sustainability is inherent within I4.0 } \\
\text { processes, directly impacting the transition toward cleaner forms of } \\
\text { energy. }\end{array}$} \\
\hline Affordable and clean energy & \\
\hline
\end{tabular}




\begin{tabular}{|c|c|}
\hline $\begin{array}{l}\text { Decent work and economic } \\
\text { growth }\end{array}$ & \multirow{3}{*}{$\begin{array}{l}\text { The transition to I } 4.0 \text { has the potential to directly impact the SDGs } \\
\text { relating to work, economic advancement and the growth of industry. } \\
\text { The greater levels of automation and I } 4.0 \text { related technological } \\
\text { advancements are forecast to reduce the reliance on the low skilled } \\
\text { workforce. Jobs will be higher skilled, higher paid where humans in } \\
\text { the loop will work with AI and robots within the manufacturing } \\
\text { environment and production infrastructure. Sustainability is a key } \\
\text { theme within I } 4.0 \text { where manufacturers will focus on increasing } \\
\text { efficiencies and reduced waste via the innovative use of sensors and } \\
\text { associated IoT technologies. These aspects will gain the greatest } \\
\text { benefit when the full supply chain is aligned with a common } \\
\text { sustainability focus. }\end{array}$} \\
\hline $\begin{array}{l}\text { Industry innovation and } \\
\text { infrastructure }\end{array}$ & \\
\hline $\begin{array}{l}\text { Sustainable cities } \\
\text { communities }\end{array}$ & \\
\hline $\begin{array}{l}\text { Responsible consumption and } \\
\text { production }\end{array}$ & \multirow{4}{*}{$\begin{array}{l}\text { Improvement in sensor and other related I } 4.0 \text { technologies such as } \\
\text { BDA and IoT offers the potential for greater levels of sustainability } \\
\text { and reduced consumption as processes become more efficient. This } \\
\text { increased focus on efficiency within manufacturing and the wider } \\
\text { supply chain will drive change from developing countries as they } \\
\text { transition toward I4.0 principles. This will directly impact emissions } \\
\text { as industry adopts more effective production techniques, less waste } \\
\text { throughout the supply chain and lessen the reliance on traditional } \\
\text { carbon based energy sources. }\end{array}$} \\
\hline Climate action & \\
\hline Life below water & \\
\hline Life on land & \\
\hline $\begin{array}{l}\text { Peace justice and } \\
\text { institutions }\end{array}$ & $\begin{array}{l}\text { These SDGs can be strengthened by the industry wide migration } \\
\text { toward I } 4.0 \text { and the transition toward the positive cultural changes } \\
\text { necessary to deliver these changes. Effective and innovative } \\
\text { manufacturing organisations with a well-trained educated workforce } \\
\text { will have a direct impact on key institutions and wider societal change. }\end{array}$ \\
\hline Partnerships for the goals & $\begin{array}{l}\text { The industry wide transition toward I4.0 requires significant } \\
\text { institutional support in the financial and legislative context. Key } \\
\text { partnerships between government, trade unions and industry will be } \\
\text { necessary for success. The lessons learned within developed markets } \\
\text { on I4.0 transition should be communicated to manufacturers within } \\
\text { emerging markets to ensure key areas of society are not left behind. }\end{array}$ \\
\hline
\end{tabular}

The alignment of the UN SDG's and I4.0 highlights the number of significant benefits that could be realised on the industry wide adoption of many of the I4.0 themes. The migration toward I4.0 could see the greatest impact within developing economies as the social and economic drivers engender greater impetus for change. These changed economies are likely to directly impact many of the UN SDGs during the transition period and thereafter as the positive effects of I4.0 and smart 
manufacturing start to take hold. These benefits within the emerging markets context are reliant on supportive government sustainability related policies, industry-wide investment and the reskilling of workers to support the I4.0 related changes to manufacturing. The successful delivery of the SDGs in the context of I4.0 will require significant institutional and industry wide support and intervention. The strategic alignment of manufacturing productivity and government economic goals is likely to be the best potential path for success.

\subsection{I4.0 Challenges in transitioning to I4.0 - a framework perspective}

Researchers have developed a number of models and frameworks that generate additional insight and theoretical contribution to the I4.0 related literature. A number of these frameworks are specific to technology elements of I4.0 such as big data or IoT whilst others concentrate on the holistic view of I4.0 Operationalization. Each of the frameworks are listed in Table 3 and have been posited as offering key contribution to the literature with new perspectives on many of the core I4.0 related topics.

Table 3 - I4.0 related frameworks

\begin{tabular}{|l|l|l|}
\hline Framework Reference & Description & I4.0 Theme \\
\hline $\begin{array}{l}\text { Caputo et al. (2016) - IoT and } \\
\text { additive manufacturing } \\
\text { framework. }\end{array}$ & $\begin{array}{l}\text { Conceptual framework aligned with the } \\
\text { interpretation and potential forecasting of impact of } \\
\text { IoT on the manufacturing industry. }\end{array}$ & $\begin{array}{l}\text { Flexible and additive } \\
\text { manufacturing } \\
\text { perspectives }\end{array}$ \\
\hline $\begin{array}{l}\text { Chien et al. (2017) - } \\
\text { framework for production big } \\
\text { data. }\end{array}$ & $\begin{array}{l}\text { Algorithm based big data framework for excursion } \\
\text { detection specific to reduction of yield loss within } \\
\text { semi-conductor manufacturing. }\end{array}$ & Big data and analytics \\
\hline $\begin{array}{l}\text { Depeige \& Doyencourt (2015) } \\
\text { Big data, knowledge } \\
\text { management in the cloud }\end{array}$ & $\begin{array}{l}\text { Knowledge based decision framework. KM } \\
\text { framework combines big data analytics and } \\
\text { Actionable Knowledge As A Service (AKAAS) } \\
\text { within a cloud computing environment. }\end{array}$ & \\
\hline
\end{tabular}




\begin{tabular}{|c|c|c|}
\hline $\begin{array}{l}\text { Fatorachian \& Kazemi (2018)- } \\
\text { Framework for } \\
\text { Operationalization of I4.0. }\end{array}$ & $\begin{array}{l}\text { Theoretical framework for Operationalization of } \\
\text { I4.0 within smart manufacturing context utilising } \\
\text { Cyber Physical Production Systems (CPPS). }\end{array}$ & $\begin{array}{l}4.0 \text { maturity and } \\
\text { roadmap }\end{array}$ \\
\hline $\begin{array}{llrl}\text { Frank et al. } & (2019) & - \\
\text { Framework } & \text { of } & \text { I4.0 } \\
\text { technologies. } & & & \end{array}$ & $\begin{array}{l}\text { I4.0 technologies framework integrating smart } \\
\text { manufacturing, smart products, smart working and } \\
\text { smart supply chain for adoption patterns of I4.0 } \\
\text { technologies. }\end{array}$ & $\begin{array}{l}\text { Intelligent manufacturing } \\
\text { and smart factory of the } \\
\text { future }\end{array}$ \\
\hline $\begin{array}{l}\text { Gunasekaran et al. (2019) - } \\
\text { BDA framework. }\end{array}$ & $\begin{array}{l}\text { Big Data Business Analytics (BDBA) framework. } \\
\text { Conceptual representation of BDBA and } \\
\text { relationship with agile manufacturing, business } \\
\text { performance and competitive objectives. }\end{array}$ & Big data and analytics \\
\hline $\begin{array}{l}\text { Kamble et al. (2018) - ISM } \\
\text { framework }\end{array}$ & $\begin{array}{l}\text { Framework identifying the interdependencies } \\
\text { between barriers for adoption of I } 4.0 \text { within Indian } \\
\text { manufacturing. }\end{array}$ & $\begin{array}{l}\text { I4.0 maturity and } \\
\text { roadmap }\end{array}$ \\
\hline $\begin{array}{l}\text { Kumar et al. (2016) - Big data } \\
\text { mapReduce framework. }\end{array}$ & $\begin{array}{l}\text { Automatic pattern recognition based framework for } \\
\text { fault diagnosis within a cloud based and big data } \\
\text { manufacturing context. }\end{array}$ & Big data and analytics \\
\hline $\begin{array}{l}\text { LaCasse et al. (2018) - Big data } \\
\text { framework }\end{array}$ & $\begin{array}{l}\text { Hierarchical feature based framework using big data } \\
\text { integrating: applied metaheuristics, machine } \\
\text { learning and fuzzy inference systems. }\end{array}$ & Big data and analytics \\
\hline $\begin{array}{l}\mathrm{Li} \text { et al. (2017) - Services } \\
\text { exchange framework }\end{array}$ & $\begin{array}{l}\text { Decentralized framework based on and edge } \\
\text { computing and blockchain technologies using: } \\
\text { customer, enterprise, application, intelligence, data } \\
\text { and infrastructure layers. }\end{array}$ & $\begin{array}{l}\text { Impact of IoT, cloud } \\
\text { computing and emerging } \\
\text { technologies }\end{array}$ \\
\hline $\begin{array}{l}\text { Papadopoulos et al. (2017)- } \\
\text { Big data disaster resilience } \\
\text { framework. }\end{array}$ & $\begin{array}{l}\text { Theoretical framework focussing on big data and } \\
\text { sustainability in the context of supply chain network } \\
\text { resilience. }\end{array}$ & $\begin{array}{l}\text { Sustainability factors and } \\
\text { impact on I } 4.0\end{array}$ \\
\hline $\begin{array}{l}\text { Rymaszewska et al. (2017) - } \\
\text { Servitisation framework. }\end{array}$ & $\begin{array}{l}\text { Conceptual framework for value creation and } \\
\text { competitive advantage using IoT for manufacturers. }\end{array}$ & $\begin{array}{l}\text { Impact of IoT, cloud } \\
\text { computing and emerging } \\
\text { technologies }\end{array}$ \\
\hline $\begin{array}{l}\text { Sanders et al. (2016) - } \\
\text { Framework for barriers and } \\
\text { challenges for lean within I4.0 } \\
\text { context }\end{array}$ & $\begin{array}{l}\text { Framework relating to barriers and challenges in the } \\
\text { application of lean within the integration of I } 4.0 \\
\text { technologies perspective. }\end{array}$ & $\begin{array}{l}\text { I4.0 maturity and } \\
\text { roadmap }\end{array}$ \\
\hline $\begin{array}{l}\text { de Sousa Jabbour et al. (2018) } \\
\text { - Integrative framework I4.0 } \\
\text { and sustainability }\end{array}$ & $\begin{array}{l}\text { Integrative framework analysing relationships } \\
\text { between environmentally sustainable manufacturing } \\
\text { and I4.0 using key Critical Success Factors (CSF). }\end{array}$ & $\begin{array}{l}\text { Sustainability factors and } \\
\text { impact on I } 4.0\end{array}$ \\
\hline $\begin{array}{l}\text { Tu et al. (2018) }- \text { IoT } \\
\text { modelling framework }\end{array}$ & $\begin{array}{l}\text { Unified modelling framework for IoT based } \\
\text { production logistics and supply chain system using } \\
\text { components of: business entity, process informatics, } \\
\text { time, location and object. }\end{array}$ & $\begin{array}{l}\text { Impact of IoT, cloud } \\
\text { computing and emerging } \\
\text { technologies }\end{array}$ \\
\hline $\begin{array}{l}\text { Zaki et al. (2017) - Big data } \\
\text { conceptual framework }\end{array}$ & $\begin{array}{l}\text { Conceptual framework detailing the emerging } \\
\text { interrelationships between big data and redistributed } \\
\text { manufacturing. }\end{array}$ & Big data and analytics \\
\hline
\end{tabular}




\begin{tabular}{|l|l|l|l|}
\hline $\begin{array}{l}\text { Zhang et al. (2018b) - } \\
\text { Framework for big data } \\
\text { acquisition. }\end{array}$ & $\begin{array}{l}\text { Big data driven analytical framework (BDDAF) for } \\
\text { manufacturer energy consumption analysis } \\
\text { consisting of: big data perception, big data mining, } \\
\text { decision making and application services. }\end{array}$ & Big data and analytics \\
\hline $\begin{array}{l}\text { Zheng et al. (2018) - Smart } \\
\text { manufacturing for I4.0 } \\
\text { framework. }\end{array}$ & $\begin{array}{l}\text { Systematic framework of smart manufacturing } \\
\text { systems for I4.0 covering: design, machining, } \\
\text { monitoring, control, scheduling and industrial } \\
\text { implementation. }\end{array}$ & $\begin{array}{l}\text { Intelligent manufacturing } \\
\text { and smart factory of the } \\
\text { future }\end{array}$ \\
\hline
\end{tabular}

A number of frameworks within the I4.0 focussed literature have utilised aspects of big data and analytics to offer insight on specific manufacturing problems and scenarios. The framework presented in Zaki et al. (2017) analysed the impact of big data within a redistributed manufacturing context, specifically - consumer goods industry cases. The framework emphasises the influences of redistributed manufacturing and co-creation on big data and subsequent impact of separate dimensions of new manufacturing technologies. The Chien (2017) study presented an algorithmic centric framework for excursion detection specific to semi-conductor manufacturers. The framework was empirically validated and positioned as offering contributing to the detection of yield loss within the production process.

Further theoretical big data frameworks have incorporated analytical perspectives to offer insight on key I4.0 related scenarios. The Big data mapReduce framework presented in Kumar (2016) uses big data analytics to develop a fault detection model for production and supply chain problem and impact scenarios. Further studies such as: Depeige \& Doyencourt (2015) and Gunasekaran et al. (2019) explore the applications of big data analytics in the context of: knowledge as a service and agile manufacturing respectively. Both frameworks posit the potential efficiencies for manufacturers in the application of the frameworks. The big data related frameworks presented in LaCasse et al. (2018) and Zhang et al. (2018b) focus on value acquisition 
from data analytics to improve efficiencies and improved processes within their respective manufacturing contexts. These specific frameworks focus on the value to manufacturers from BDA and the criticality of interpretation of analytics for key decision making within the organisation.

Researchers have developed a number of models and frameworks incorporating concepts related to the value of IoT and emerging technologies to the performance of manufacturers. The services exchange framework presented in Li et al. (2017) predominantly addresses sharing knowledge and services utilising blockchain technologies. The framework highlights some of the issues relating to open manufacturing and use the attributes of blockchain to facilitate knowledge exchange between the different parties within the ecosystem. The IoT system framework presented in Tu et al. (2018) supports the modelling and reduction in design complexity for manufacturers concerned with production logistics and supply chain systems. The theme of value is inherent within the framework presented in Rymaszewska et al. (2017) where they present a conceptual framework based on usage of IoT technologies. The framework posits the concept of value creation through the IoT and application of servitisation principles.

The concept of the smart factory and the transition to intelligent manufacturing has been adopted within a number of frameworks. The research undertaken by Frank et al. (2019) included a theoretical framework integrating the smart front end I4.0 technologies with the so called - base technologies such as IoT and BDA. The study by Zheng et al. (2018) also analysed the smart aspects of I4.0, developing a conceptual framework for manufacturing systems by integrated a number of smart I 4.0 concepts within a matrix of design, production and monitoring elements. The Zheng et al. (2018) and Frank et al. (2019) studies highlighted a number of demonstrable I4.0 specific scenarios and technological adoption patterns. One of the key findings within Frank et al. 
(2019) and subsequent framework, is the realisation that the transition toward I4.0 is staged based, somewhat analogous to "Lego" where the technological advancements are an increment or step along the road to I4.0 maturity. The conceptual framework proposed in Caputo et al. (2016) posits the value in the interpretation of evolutionary factors relating to IoT and the manufacturing industry. The framework highlights the contribution of IoT and potential influence on organisations within an adaptive manufacturing environment. The study highlights the technical bias of previous research presenting the novelty of applying the framework to innovation from the management perspective (Caputo et al. 2016).

The increasing role of sustainability within the manufacturing, operations and supply chain literature highlights the ongoing debates and focus on responsible manufacturing. The theoretical framework presented in Papadopoulos et al. (2017) was developed from an assessment of top priorities for supply chain resilience. The framework integrates trust and information sharing elements with resilience factors within infrastructure and supply chain networks. The sustainability focus was further developed in the study by de Sousa Jabbour et al. (2018), where the research presented an integrative framework for the advancement of I4.0 technologies integrated with environmentally sustainable manufacturing.

Researchers have developed a number of frameworks aligned with transition to I4.0 and some of the challenges faced by organisations during I4.0 Operationalization. The I4.0 operationalization framework developed in Fatorachian \& Kazemi (2018) addresses the interconnectivity of machinery and systems with the manufacturing environment and how CPS elements interact with the cloud and external networks. This specific framework offers a smart manufacturing and technology adoption perspective. The frameworks presented in Sanders et al. 
(2016) and Kamble et al. (2018) emphasis the impact of organisations migrating to I4.0 and interdependence between the barriers relating to I4.0 adoption.

Whilst generating insight and conceptualisation, the presented frameworks offer focus and perspective on limited elements of the overall themes relating to I4.0 technologies and application. The framework presented in Fatorachian \& Kazemi (2018) for the Operationalization of I4.0, details a number of the key themes highlighted within this study. The I4.0 operationalization framework develops the concept of a Cyber Physical Production Systems (CPPS) environment, where the proposed framework architecture posits the roles of the CPPS enabler and CPPS information server as key steps for smart manufacturing transformation. The framework (presented in simplified form in Figure 3) identifies the criticality of high levels of interconnectivity and integration between machinery, sensors and systems within an overall IoT enabled manufacturing environment (Fatorachian \& Kazemi 2018).

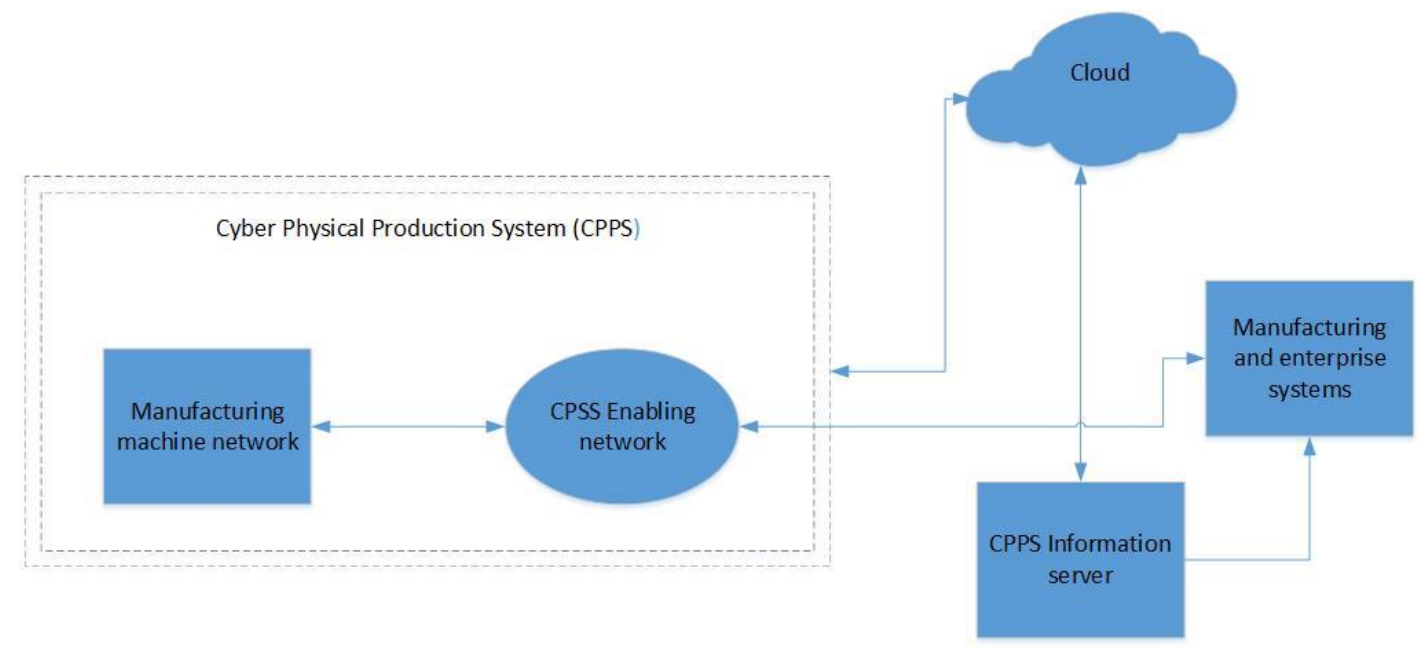

Figure 3: I4.0 operationalization framework - adapted from Fatorachian \& Kazemi 2018 (simplified) 
The novelty inherent within the Fatorachian \& Kazemi (2018) I4.0 framework connecting the physical production environment through the CPPS enabler to the CPPS server, perhaps lacks perspective on some of the critical process and analytics perspectives as well as explicit reference to I4.0 transition complexities. Some of these elements are referenced in the Frank et al. (2019) framework where the concepts of a staged migration to I4.0 is posited based on the addition of technological building blocks. In an attempt to fill these gaps and extend some of the key factors from the existing research, we present the I4.0 transition framework in figure 4.

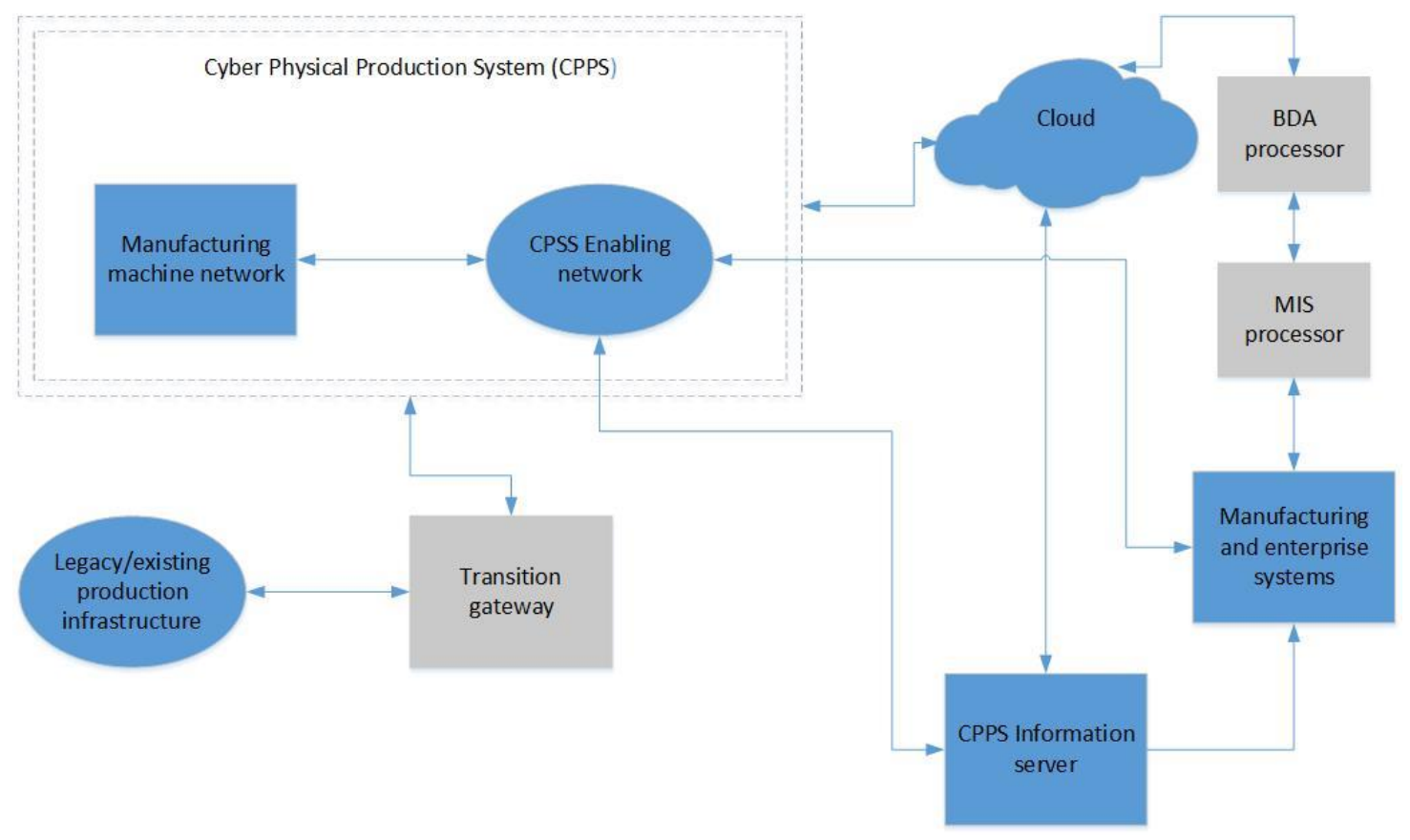

Figure 4: I4.0 transition framework (adapted from Fatorachian \& Kazemi 2018 and Frank et al. 2019)

This I4.0 transition framework details the addition of three new components, namely: 1) transition gateway, 2) BDA processor and 3) MIS processor. The addition of these elements to the framework 
reflects some of the key implementation factors within Frank et al. (2019) and I4.0 maturity pathway.

Transition gateway: This addition to the framework represents the existing production capacity during the transition to I4.0 and the reality that manufacturers are likely to be migrating to I4.0 capability over time. This necessitates the ongoing operations of existing production infrastructure whilst core elements of capacity are migrated to I4.0. Manufacturers will need to maintain existing production and ensure that the existing infrastructure and processes can communicate with the new I4.0 related systems. This phased approach is supported in the literature where the roadmap to I4.0 is articulated as a phased technological approach to increasing levels of capability reflecting industrial realities faced by manufacturers (Frank et al. 2019; Mittal et al. 2018).

BDA Processor: The literature has identified the pivotal role of analytics in the big data era and the criticality of the intelligent use of data for key decision making within the organisation. This addition to the framework is positioned as a processing element directly connected to cloud based systems that performs the necessary BDA functions. The importance of big data is referenced in the Fatorachian \& Kazemi (2018) study and somewhat implicit within the framework under the cloud systems component. However, this addition to the framework outlines the criticality of BDA and its place as a core element of any I4.0 focussed architecture (Mousannif et al. 2016; Muhuri et al. 2019).

MIS processor: The management information systems processor component - reflects the requirement for relevant and timely data reflecting performance, efficiencies and productivity within the production and overall manufacturing context. This element will develop the statistical evidence base for the transition period and full operationalization to I4.0. Elements of this component may be present within existing enterprise systems, however, for the purpose of this 
framework scenario, it is assumed that existing systems may not offer the required flexibility or capacity for the organisation. The literature has reinforced the emphasis toward an evidence based transition for I4.0 and migration toward increased levels of automation, yield, flexibility, productivity and manufacturing efficiency (Auschitzky et al. 2014; Buer et al. 2018; Pereira \& Romero 2017). The I4.0 transition framework is presented as an addition to theory highlighting the criticality of the additional components and the case for their inclusion within the overall framework architecture. The framework supports many of the key transition complexities and focus on the realities of a step by step systemised approach to I4.0 capability within many organisations.

\subsection{Theoretical and Managerial Implications}

This study directly contributes to the existing body of knowledge by extending the analysis and discussion surrounding I4.0 and the manufacturing sector from a number of important perspectives. Specifically, this research via the selection and evaluation of relevant themes, offers a valuable perspective on many of the technological, theoretical, societal and industrial factors facing manufacturers and government organisations. The transition to I4.0 is complex with significant implications not just for manufactures, but for the wider supply chain, major institutions and for governments. Many of the I4.0 related technologies such as IoT, big data, CPS and adoption of increasing elements of AI discussed in this study, offer significant opportunities for manufacturers in the context of productivity and increased efficiencies. However, I4.0 requires committed institutional support and major investment in manufacturing infrastructure and integration of technology (Li 2018; Ismail et al. 2019; RS Connected Thinking 2019). 
The focus within this study on the impact of I4.0 from the emerging markets perspective highlights the many challenges facing worker led industries with low levels of automation lacking the necessary infrastructure to easily transition to smart factories. The impact on these economies is likely be significant. We highlight the critical key role of Government and industry leaders in the alignment of strategic aims, to provide the necessary investment and policy directives to retrain and re-educate workers to ensure emerging economies can effectively compete within the new global market. The societal implications of this not being actioned effectively, are significant and could impact whole communities who's skills are out of date and no longer required within a fast changing manufacturing environment.

The sustainability aspects of I4.0 analysed in this study as well as alignment of related benefits and outcomes to the UN SDG's, offers an additional theoretical contribution where the wider societal, cultural and sustainability aspects of smart and intelligent manufacturing are impacted. The industry wide adoption of I4.0 will require significant change across many levels of industry and society requiring new skills, technological adoption and adapted manufacturing processes. Many of these changes have the potential to contribute to the attainment of the SDG's, however, if the required strategic investment to effectively manage the change to I4.0 is not made, emerging markets will be left behind and many of the health and wellbeing related SDG's may not be met.

Organisations are likely to migrate to I4.0 in stages whilst transitioning key elements of their business processes as they build operational capability (Ghobakhloo 2018; Haeffner \& Panuwatwanich 2017). The I4.0 transition framework is presented in this study as a contribution to theory recognising the reality that many manufacturers will need to build a production infrastructure that allows operational integration with existing and new processes. As manufacturers migrate toward greater levels of I4.0 maturity along a structured roadmap, effective 
analytics are critical. The BDA and MIS processing elements of the I4.0 transition framework reflect the role of timely data analysis for key management decision making on operational effectiveness and productivity.

\subsection{Future research agenda}

This study has discussed a number of key I4.0 related topics that have the potential for significant industrial and societal impact as manufacturers transition to I4.0 and greater levels of automation. This is likely to affect countries within emerging markets disproportionately, as they have traditionally operated under the low paid, low skilled labour intensive model, sensitive to factory reorganisation and automation (Haeffner \& Panuwatwanich 2017). Change in these sectors are societal in nature where large numbers of the workforce will need educating and retraining to meet the new skills and expertise required for I4.0 technologies and working processes. Further research to identify methods, processes and migration frameworks to offer increased understanding of the impact on emerging economies could offer meaningful insight to this important area. Furthermore, opportunities exists for emerging markets manufacturers to learn the lessons of I4.0 transition from the experience of developed economies. Relevant research that could analyse many of the key areas of lessons learned, potentially offering an adapted I4.0 emerging markets specific roadmap, could offer significant contribution.

\section{Conclusions}

The migration toward I4.0 has the potential for disruptive change within the manufacturing sector over the next decade or so, as developed and emerging economies develop their individual 
roadmaps to I4.0 maturity. The increasing levels of automation, reliance on CPS, big data, IoT and IA reflect an industry wide migration toward flexible, adaptable and smart manufacturing. The impact on factory workers and production processes is significant due changing landscape of skills requirements and flexibility to cater for a growing need for customisation. The concept of increasing levels of automation with a human in the loop, seems to be the consensus within the literature where machines are likely to augment human skills and endeavours within the production environment. The successful migration toward I4.0 requires strategic institutional support and significant sector-wide financial investment. The benefits of the German example of defining a strategic roadmap to I4.0 has gained widespread recognition within the literature as many countries see this as a desirable model for their domestic transition to I4.0 maturity. The emerging manufacturing economies of China and India whilst currently lagging behind a number of the developed economies, are predicted to rise significantly over the next few years via the adoption of I4.0 technologies.

This study has focussed on the analysis of I4.0 within the manufacturing context, based on the assessment of a number of technological and operationally relevant emergent themes via a structured literature review. Each of these themes have been analysed and discussed to highlight the key salient points and critical factors that impact manufacturers. The challenges for developed and emerging markets has been discussed as well as the sustainability factors that impact I4.0 and smart manufacturing. The inclusion of the UN SDG's and their establishment of a shared agenda and blueprint for peace and prosperity for the planet and population, highlights a number of the potential shared outcomes from I4.0 maturity and progression of the manufacturing workforce to higher levels in the value chain of manufacturing. The proposed framework is presented from the perspective of the realities of a step by step staged roadmap to I4.0 operational effectiveness. 
Manufacturers are likely to need to retain current operational capability whilst specific processes within their production architecture are transitioned. The path to I4.0 maturity offers significant long term benefits and transformative potential for the economies concerned as they migrate toward the smart factory of the future.

Whilst this study is positioned as offering contribution to the literature, the research is perhaps limited by lack of empirical evaluation of the I4.0 transition framework within the context of a representative case study. Further study is recommended to explore the viability of the framework within a representative scenario.

\section{References}

Additive Manufacturing (2019). AM Basics. Accessed in May 2019. http://additivemanufacturing.com/basics/

Ahuett-Garza, H., \& Kurfess, T. (2018). A brief discussion on the trends of habilitating technologies for Industry 4.0 and Smart manufacturing. Manufacturing Letters, 15, 60-63.

Almada-Lobo, F. (2016). The Industry 4.0 revolution and the future of manufacturing execution systems (MES). Journal of innovation management, 3(4), 16-21.

Auschitzky, E., Hammer, M., \& Rajagopaul, A. (2014). How big data can improve manufacturing. McKinsey \& Company, 822 .

https://digitalstrategy.nl/wp-content/uploads/2014.01-A-How-big-data-can-improvemanufacturing-_-McKinsey-Company.pdf

Baines, T., Ziaee Bigdeli, A., Bustinza, O. F., Shi, V. G., Baldwin, J., \& Ridgway, K. (2017). Servitization: revisiting the state-of-the-art and research priorities. International Journal of Operations \& Production Management, 37(2), 256-278.

Barenji, A. V., Li, Z., \& Wang, W. M. (2018, June). Blockchain cloud manufacturing: Shop floor and machine level. In Smart SysTech 2018; European Conference on Smart Objects, Systems and Technologies (pp. 1-6). VDE.

BBC (2019). Making a better future. Accessed in May 2019. http://www.bbc.com/future/bespoke/the-disruptors/making-a-better-future/\#sa-

link_location=features-and-analysis-

6\&intlink_from_url=https\%3A\%2F\%2Fwww.bbc.co.uk\%2Fnews\%2Fuk-england-leeds$\underline{47798868 \& \text { intlink_ts }=1554290792118 \& \text { story_slot }=1 \text {-sa }}$ 
Ben-Daya, M., Hassini, E., \& Bahroun, Z. (2017). Internet of things and supply chain management: a literature review. International Journal of Production Research, 1-24.

Birge, J. R. (2018). Book Review: Xinbao Liu, Jun Pei, Lin Liu, Hao Cheng, Mi Zhou, and Panos M. Pardalos: Optimization and management in manufacturing engineering. Resource collaborative optimization and management through the Internet of Things. Springer optimization and its applications series. Journal of Global Optimization, 1-2.

Braccini, A. M., \& Margherita, E. G. (2018). Exploring Organizational Sustainability of Industry 4.0 under the Triple Bottom Line: The Case of a Manufacturing Company. Sustainability, 11(1), 1-17.

Brettel, M., Friederichsen, N., Keller, M., \& Rosenberg, M. (2014). How virtualization, decentralization and network building change the manufacturing landscape: An industry 4.0 perspective. International journal of mechanical, industrial science and engineering, 8(1), 37-44.

Brock, V., \& Khan, H. U. (2017). Big data analytics: Does organizational factor matters impact technology acceptance? Journal of Big Data, 4(1) doi:10.1186/s40537-017-0081-8.

Buer, S. V., Strandhagen, J. O., \& Chan, F. T. (2018). The link between Industry 4.0 and lean manufacturing: mapping current research and establishing a research agenda. International Journal of Production Research, 56(8), 2924-2940.

Burnes, B., \& Towers, N. (2016). Consumers, clothing retailers and production planning and control in the smart city. Production Planning \& Control, 27(6), 490-499.

Caputo, A., Marzi, G., \& Pellegrini, M. M. (2016). The internet of things in manufacturing innovation processes: development and application of a conceptual framework. Business Process Management Journal, 22(2), 383-402.

Cardoso, W., Júnior, W. A., Bertosse, J. F., Bassi, E., \& Ponciano, E. S. (2017). Digital manufacturing, industry 4.0, clould computing and thing internet: Brazilian contextualization and reality. Independent Journal of Management \& Production, 8(2), 459-473.

Chang, V. I., \& Lin, W. (2019). How Big Data Transforms Manufacturing Industry: A Review Paper. International Journal of Strategic Engineering (IJoSE), 2(1), 39-51.

Cheng, Y., Tao, F., Xu, L., \& Zhao, D. (2018). Advanced manufacturing systems: supply-demand matching of manufacturing resource based on complex networks and Internet of Things. Enterprise Information Systems, 12(7), 780-797.

Chien, C. F., Liu, C. W., \& Chuang, S. C. (2017). Analysing semiconductor manufacturing big data for root cause detection of excursion for yield enhancement. International Journal of Production Research, 55(17), 5095-5107.

Contreras, L., \& Perez, J. (2018). Importance of the Use of the Internet of Things and its Implications in the Manufacturing Industry. European Scientific Journal, ESJ, 14(10).

Cooley, J., \& Petrusich, J. (2013, July). Delivering optimal real-time manufacturing intelligence. In 2013 Proceedings of PICMET'13: Technology Management in the IT-Driven Services (PICMET) (pp. 1658-1668). IEEE. 
Cardoso, W., Júnior, W. A., Bertosse, J. F., Bassi, E., \& Ponciano, E. S. (2017). Digital manufacturing, industry 4.0, clould computing and thing internet: Brazilian contextualization and reality. Independent Journal of Management \& Production, 8(2), 459-473.

Depeige, A., \& Doyencourt, D. (2015). Actionable knowledge as A service (AKAAS): Leveraging big data analytics in cloud computing environments. Journal of Big Data,2(1) doi:10.1186/s40537-015-0023-2.

Du, C. Z., \& Yang, Z. K. (2015). Inspiration of transformation and upgrading of manufacturing industry in China from German industry 4.0 strategy. Research on Economics and Management, 36(7), 82-87.

DIN \& DKE (2018). German Standardization Roadmap Industrie 4.0. V3. Accessed on 25 $5^{\text {th }}$ April 2019. https://www.din.de/blob/65354/57218767bd6da1927b181b9f2a0d5b39/roadmap-i4-0e-data.pdf

Fang, C., Liu, X., Pei, J., Fan, W., \& Pardalos, P. M. (2016). Optimal production planning in a hybrid manufacturing and recovering system based on the internet of things with closed loop supply chains. Operational Research, 16(3), 543-577.

Fatorachian, H., \& Kazemi, H. (2018). A critical investigation of Industry 4.0 in manufacturing: theoretical Operationalization framework. Production Planning \& Control, 29(8), 633-644.

Ferrera, E., Rossini, R., Baptista, A. J., Evans, S., Hovest, G. G., Holgado, M., ... \& Silva, E. J. (2017, April). Toward Industry 4.0: efficient and sustainable manufacturing leveraging MAESTRI total efficiency framework. In International Conference on Sustainable Design and Manufacturing (pp. 624-633). Springer, Cham.

Frank, A. G., Dalenogare, L. S., \& Ayala, N. F. (2019). Industry 4.0 technologies: implementation patterns in manufacturing companies. International Journal of Production Economics, 210, 15-26.

Frolov, V. G., Kaminchenko, D. I., Kovylkin, D. Y., Popova, J. A., \& Pavlova, A. A. (2017). The main economic factors of sustainable manufacturing within the industrial policy concept of industry 4.0. Academy of Strategic Management Journal, 16(Special issue 2).

Fujino, N., \& Konno, Y. (2016). Industry 4.0 and significance for Japanese manufacturing. Nomura Research Institute, 210.

Gandomi, A., \& Haider, M. (2015). Beyond the hype: Big data concepts, methods, and analytics. International Journal of Information Management, 35(2), 137-144.

Gao, W., Zhang, Y., Ramanujan, D., Ramani, K., Chen, Y., Williams, C. B., \& Zavattieri, P. D. (2015). The status, challenges, and future of additive manufacturing in engineering. Computer-Aided Design, 69, 65-89.

Gentner, S. (2016). Industry 4.0: Reality, Future or just Science Fiction? How to Convince Today's Management to Invest in Tomorrow's Future! Successful Strategies for Industry 4.0 and Manufacturing IT. CHIMIA International Journal for Chemistry, 70(9), 628-633. 
Genovese, A., Lenny Koh, S. C., Kumar, N., \& Tripathi, P. K. (2014). Exploring the challenges in implementing supplier environmental performance measurement models: a case study. Production Planning \& Control, 25(13-14), 1198-1211.

Ghafoorpoor Yazdi, P., Azizi, A., \& Hashemipour, M. (2018). An empirical investigation of the relationship between overall equipment efficiency (OEE) and manufacturing sustainability in Industry 4.0 with time study approach. Sustainability, 10(9), 3031.

Ghobakhloo, M. (2018). The future of manufacturing industry: A strategic roadmap toward Industry 4.0. Journal of Manufacturing Technology Management, 29(6), 910-936

Grieves, M., \& Vickers, J. (2017). Digital twin: Mitigating unpredictable, undesirable emergent behavior in complex systems. In Transdisciplinary perspectives on complex systems (pp. 85113). Springer, Cham.

Gunasekaran, A., Yusuf, Y. Y., Adeleye, E. O., \& Papadopoulos, T. (2018). Agile manufacturing practices: the role of big data and business analytics with multiple case studies. International Journal of Production Research, 56(1-2), 385-397.

Helo, P., \& Hao, Y. (2017). Cloud manufacturing system for sheet metal processing. Production Planning \& Control, 28(6-8), 524-537.

Haeffner, M., \& Panuwatwanich, K. (2017, September). Perceived Impacts of Industry 4.0 on Manufacturing Industry and Its Workforce: Case of Germany. In International Conference on Engineering, Project, and Product Management (pp. 199-208). Springer, Cham.

Hang, Z., Ruiqian, L., \& Yue, Y. (2014). Investigation of the Datamation of Manufacturing Industrial Chain in the Big Data Era. Applied Mechanics \& Materials.

Hauer, G., Harte, P., \& Kacemi, J. (2018). An exploration of the impact of industry 4.0 approach on corporate communication in the german manufacturing industry. International Journal of Supply Chain Management, 7(4), 125-131.

Hughes, L., Dwivedi, Y. K., Misra, S. K., Rana, N. P., Raghavan, V., \& Akella, V. (2019). Blockchain research, practice and policy: Applications, benefits, limitations, emerging research themes and research agenda. International Journal of Information Management, 49, 114-129.

Ismail, A., Truong, H. -., \& Kastner, W. (2019). Manufacturing process data analysis pipelines: A requirements analysis and survey. Journal of Big Data, 6(1) doi:10.1186/s40537-018-0162-3.

Ismagilova, E., Hughes, L., Dwivedi, Y.K. and Raman, K.R., 2019. Smart cities: Advances in research-An information systems perspective. International Journal of Information Management, 47, 88-100.

Jain, P. K., \& Mosier, C. T. (1992). Artificial intelligence in flexible manufacturing systems. International Journal of Computer Integrated Manufacturing, 5(6), 378-384.

Jayaraman, R., Basu, A., \& Chakraborty, S. (2018). Internet Of Things And The Future Of Manufacturing Industry. Indian Journal of Computer Science, 3(3), 7-25. 
Jeschke, S., Brecher, C., Meisen, T., Özdemir, D., \& Eschert, T. (2017). Industrial internet of things and cyber manufacturing systems. In Industrial Internet of Things (pp. 3-19). Springer, Cham.

Jimenez, J. A., Ramasubramanian, A., \& Psimenos, G. IoT based Blockchain for Manufacturing Process Monitoring and Logistics within an Organisation. Accessed April 2019. http://ajulio.com/assets/documents/Blockchain.pdf

Jonsson, A., \& Svensson, V. (2016). Systematic Lead Time Analysis. Chalmers University of Technology. Accessed April 2019. http://www.publications.lib.chalmers.se/records/fulltext/238746/238746. Pdf.

Jung, K., Choi, S., Kulvatunyou, B., Cho, H., \& Morris, K. C. (2017). A reference activity model for smart factory design and improvement. Production planning \& control, 28(2), 108-122.

Kagermann, H., Lukas, W. D., \& Wahlster, W. (2011). Industrie 4.0: Mit dem Internet der Dinge auf dem Weg zur 4. industriellen Revolution. VDI nachrichten, 13(1).

Kamble, S. S., Gunasekaran, A., \& Sharma, R. (2018). Analysis of the driving and dependence power of barriers to adopt industry 4.0 in Indian manufacturing industry. Computers in Industry, 101, 107-119.

Katz, Y. (2017). Manufacturing an artificial intelligence revolution. Available at SSRN 3078224.

Khan, A., \& Turowski, K. (2016). A survey of current challenges in manufacturing industry and preparation for industry 4.0. In Proceedings of the First International Scientific Conference "Intelligent Information Technologies for Industry"(IITI'16) (pp. 15-26). Springer, Cham.

Kiel, D., Arnold, C., \& Voigt, K. I. (2017). The influence of the Industrial Internet of Things on business models of established manufacturing companies-A business level perspective. Technovation, 68, 4-19.

Ko, T., Lee, J., \& Ryu, D. (2018). Blockchain Technology and Manufacturing Industry: Real-Time Transparency and Cost Savings. Sustainability, 10(11), 4274.

Kumar, A., Shankar, R., Choudhary, A., \& Thakur, L. S. (2016). A big data MapReduce framework for fault diagnosis in cloud-based manufacturing. International Journal of Production Research, 54(23), 7060-7073.

Kumar, S. L. (2017). State of the art-intense review on artificial intelligence systems application in process planning and manufacturing. Engineering Applications of Artificial Intelligence, 65, 294-329.

Kusiak, A. (1987). Artificial intelligence and operations research in flexible manufacturing systems. INFOR: Information Systems and Operational Research, 25(1), 2-12.

Lalic, B., Majstorovic, V., Marjanovic, U., Delić, M., \& Tasic, N. (2017, September). The effect of industry 4.0 concepts and e-learning on manufacturing firm performance: evidence from transitional economy. In IFIP International Conference on Advances in Production Management Systems (pp. 298-305). Springer, Cham. 
LaCasse, P. M., Otieno, W., \& Maturana, F. P. (2018). A hierarchical, fuzzy inference approach to data filtration and feature prioritization in the connected manufacturing enterprise. Journal of Big Data, 5(1) doi:10.1186/s40537-018-0155-2.

Lasi, H., Fettke, P., Kemper, H. G., Feld, T., \& Hoffmann, M. (2014). Industry 4.0. Business \& information systems engineering, 6(4), 239-242.

Lee, J., Davari, H., Singh, J., \& Pandhare, V. (2018). Industrial artificial intelligence for industry 4.0-based manufacturing systems. Manufacturing letters, 18, 20-23.

Lee, J. H. (2002). Artificial intelligence-based sampling planning system for dynamic manufacturing process. Expert Systems with Applications, 22(2), 117-133.

Li, F., Nucciarelli, A., Roden, S., \& Graham, G. (2016). How smart cities transform operations models: a new research agenda for operations management in the digital economy. Production Planning \& Control, 27(6), 514-528.

Li, L. (2018). China's manufacturing locus in 2025: With a comparison of "Made-in-China 2025" and "Industry 4.0". Technological Forecasting and Social Change, 135, 66-74.

Li, B. H., Hou, B. C., Yu, W. T., Lu, X. B., \& Yang, C. W. (2017). Applications of artificial intelligence in intelligent manufacturing: a review. Frontiers of Information Technology \& Electronic Engineering, 18(1), 86-96.

Li, Z., Wang, W. M., Liu, G., Liu, L., He, J., \& Huang, G. Q. (2018). Toward open manufacturing: A cross-enterprises knowledge and services exchange framework based on blockchain and edge computing. Industrial Management \& Data Systems, 118(1), 303-320.

Liao, Y., Deschamps, F., Loures, E. D. F. R., \& Ramos, L. F. P. (2017). Past, present and future of Industry 4.0-a systematic literature review and research agenda proposal. International journal of production research, 55(12), 3609-3629.

Liu, Y., \& Xu, X. (2017). Industry 4.0 and cloud manufacturing: A comparative analysis. Journal of Manufacturing Science and Engineering, 139(3), 034701.

Löffler, M., \& Tschiesner, A. (2013). The Internet of Things and the future of manufacturing. McKinsey \& Company, Accessed in April 2019. https://www.mckinsey.com/business-functions/digital-mckinsey/our-insights/the-internet-ofthings-and-the-future-of-manufacturing

Lu, Y. (2017). Industry 4.0: A survey on technologies, applications and open research issues. Journal of Industrial Information Integration, 6, 1-10.

Maddern, H., Smart, P. A., Maull, R. S., \& Childe, S. (2014). End-to-end process management: implications for theory and practice. Production Planning \& Control, 25(16), 1303-1321.

Makridakis, S. (2018). Forecasting the Impact of Artificial Intelligence, Part 3 of 4: The Potential Effects of AI on Businesses, Manufacturing, and Commerce. Foresight: The International Journal of Applied Forecasting, (49), 18-27.

Marr, B. (2015). Big Data: Using SMART big data, analytics and metrics to make better decisions and improve performance. John Wiley \& Sons. 
Mittal, S., Khan, M. A., Romero, D., \& Wuest, T. (2018). A critical review of smart manufacturing \& Industry 4.0 maturity models: Implications for small and medium-sized enterprises (SMEs). Journal of manufacturing systems, 49, 194-214.

Moher, D., Liberati, A., Tetzlaff, J., \& Altman, D. G. (2009). Preferred reporting items for systematic reviews and meta-analyses: the PRISMA statement. Annals of internal medicine, 151(4), 264-269.

Mourtzis, D., Fotia, S., Boli, N., \& Vlachou, E. (2019). Modelling and quantification of industry 4.0 manufacturing complexity based on information theory: a robotics case study. International Journal of Production Research, 1-14.

Mousannif, H., Sabah, H., Douiji, Y., \& Oulad Sayad, Y. (2016). Big data projects: just jump right in!. International Journal of Pervasive Computing and Communications, 12(2), 260-288

Muhuri, P. K., Shukla, A. K., \& Abraham, A. (2019). Industry 4.0: A bibliometric analysis and detailed overview. Engineering Applications of Artificial Intelligence, 78, 218-235.

Müller, J., Dotzauer, V., \& Voigt, K. I. (2017). Industry 4.0 and its impact on reshoring decisions of German manufacturing enterprises. In Supply Management Research (pp. 165-179). Springer Gabler, Wiesbaden.

Nikolic, B., Ignjatic, J., Suzic, N., Stevanov, B., \& Rikalovic, A. (2017). Predictive Manufacturing Systems in Industry 4.0: Trends, Benefits and Challenges. Annals of DAAAM \& Proceedings, 28.

O’Donovan, P., Leahy, K., Bruton, K., \& O’Sullivan, D. T. J. (2015). An industrial big data pipeline for data-driven analytics maintenance applications in large-scale smart manufacturing facilities. Journal of Big Data, 2(1) 20.

Oesterreich, T. D., \& Teuteberg, F. (2016). Understanding the implications of digitisation and automation in the context of Industry 4.0: A triangulation approach and elements of a research agenda for the construction industry. Computers in Industry, 83, 121-139.

Olshannikova, E., Ometov, A., Koucheryavy, Y., \& Olsson, T. (2015). Visualizing big data with augmented and virtual reality: Challenges and research agenda. Journal of Big Data, 2(1) doi:10.1186/s40537-015-0031-2.

OECD - Organisation for Economic Co-operation and Development (2014), Seven Steps to Environmental Excellence, Paris, France, 2014.

Papadopoulos, T., Gunasekaran, A., Dubey, R., Altay, N., Childe, S. J., \& Fosso-Wamba, S. (2017). The role of Big Data in explaining disaster resilience in supply chains for sustainability. Journal of Cleaner Production, 142, 1108-1118.

Papakostas, N., O'Connor, J., \& Byrne, G. (2016, October). Internet of things technologies in manufacturing: Application areas, challenges and outlook. In 2016 International Conference on Information Society ( $i$-Society) (pp. 126-131). IEEE.

Pappas, I. O., P. Mikalef, M. N. Giannakos, J. Krogstie and G. Lekakos (2018). "Big data and business analytics ecosystems: paving the way towards digital transformation and sustainable societies." Information Systems and e-Business Management 16(3): 479-491. 
Park, S., \& Huh, J. H. (2018). Effect of Cooperation on Manufacturing IT Project Development and Test Bed for Successful Industry 4.0 Project: Safety Management for Security. Processes, 6(7), 88.

Pereira, A. C., \& Romero, F. (2017). A review of the meanings and the implications of the Industry 4.0 concept. Procedia Manufacturing, 13, 1206-1214.

Pikas, B., Zhang, X., Peek, W. A., \& Lee, T. (2016). The transformation and upgrading of the Chinese manufacturing industry: Based on "German Industry 4.0". Journal of Applied Business and Economics, 18(5).

Qi, Q., \& Tao, F. (2018). Digital twin and big data towards smart manufacturing and industry 4.0: 360 degree comparison. Ieee Access, 6, 3585-3593.

Qin, J., Liu, Y., \& Grosvenor, R. (2016). A categorical framework of manufacturing for industry 4.0 and beyond. Procedia Cirp, 52, 173-178.

Rashid, A., \& Tjahjono, B. (2016). Achieving manufacturing excellence through the integration of enterprise systems and simulation. Production Planning \& Control, 27(10), 837-852.

Reischauer, G. (2018). Industry 4.0 as policy-driven discourse to institutionalize innovation systems in manufacturing. Technological Forecasting and Social Change, 132, 26-33.

Renzi, C., Leali, F., Cavazzuti, M., \& Andrisano, A. O. (2014). A review on artificial intelligence applications to the optimal design of dedicated and reconfigurable manufacturing systems. The International Journal of Advanced Manufacturing Technology, 72(1-4), 403418.

Romero, D., \& Molina, A. (2011). Collaborative networked organisations and customer communities: value co-creation and co-innovation in the networking era. Production Planning \& Control, 22(5-6), 447-472.

Rosenburg, L; Willcox, G, (2019). Artificial Swarm Intelligence. Accessed April 2019. https://11s1ty2quyfy2qbmao3bwxzc-wpengine.netdna-ssl.com/wpcontent/uploads/2019/01/Artificial-Swarm-Intelligence-white-paper-1-21-19.pdf

RS Connected Thinking (2019). The Future of Industry 4.0. Accessed March 2019. https://www.rs-connectedthinking.com/en/insights-1-1/the-future-of-industry-4-0

Rüßmann, M., Lorenz, M., Gerbert, P., Waldner, M., Justus, J., Engel, P., \& Harnisch, M. (2015). Industry 4.0: The future of productivity and growth in manufacturing industries. Boston Consulting Group, 9(1), 54-89.

Rymaszewska, A., Helo, P., \& Gunasekaran, A. (2017). IoT powered servitization of manufacturing-an exploratory case study. International Journal of Production Economics, 192, 92-105.

Sanders, A., Elangeswaran, C., \& Wulfsberg, J. P. (2016). Industry 4.0 implies lean manufacturing: Research activities in industry 4.0 function as enablers for lean manufacturing. Journal of Industrial Engineering and Management (JIEM), 9(3), 811-833. 
Santos, M. Y., e Sá, J. O., Andrade, C., Lima, F. V., Costa, E., Costa, C., ... \& Galvão, J. (2017). A big data system supporting bosch braga industry 4.0 strategy. International Journal of Information Management, 37(6), 750-760.

Sayar, D., \& Er, Ö. (2018). The antecedents of successful IoT service and system design: Cases from the manufacturing industry. International Journal of Design, 12(1), 67-78.

Schumacher, A., Erol, S., \& Sihn, W. (2016). A maturity model for assessing Industry 4.0 readiness and maturity of manufacturing enterprises. Procedia Cirp, 52, 161-166.

Shamsuzzoha, A., Toscano, C., Carneiro, L. M., Kumar, V., \& Helo, P. (2016). ICT-based solution approach for collaborative delivery of customised products. Production Planning \& Control, 27(4), 280-298.

Shridhar, V. S. (2019). The India of Things: Tata Communications' countrywide IoT network aims to improve traffic, manufacturing, and health care. IEEE Spectrum, 56(02), 42-47.

Shukla, N., Tiwari, M. K., \& Beydoun, G. (2018). Next generation smart manufacturing and service systems using big data analytics, Computers \& Industrial Engineering, 128, 905-910.

Spanaki, K., Gürgüç, Z., Adams, R., \& Mulligan, C. (2018). Data supply chain (DSC): research synthesis and future directions. International Journal of Production Research, 56(13), 44474466.

de Sousa Jabbour, A. B. L., Jabbour, C. J. C., Foropon, C., \& Godinho Filho, M. (2018). When titans meet-Can industry 4.0 revolutionise the environmentally-sustainable manufacturing wave? The role of critical success factors. Technological Forecasting and Social Change, 132, 18-25.

Strandhagen, J. W., Alfnes, E., Strandhagen, J. O., \& Vallandingham, L. R. (2017). The fit of Industry 4.0 applications in manufacturing logistics: a multiple case study. Advances in Manufacturing, 5(4), 344-358.

Sommer, L. (2015). Industrial revolution-industry 4.0: Are German manufacturing SMEs the first victims of this revolution?. Journal of Industrial Engineering and Management, 8(5), 15121532 .

Szalavetz, A. (2018). Industry 4.0 and capability development in manufacturing subsidiaries. Technological Forecasting and Social Change.

Tao, F., \& Zhang, M. (2017). Digital twin shop-floor: a new shop-floor paradigm towards smart manufacturing. Ieee Access, 5, 20418-20427.

Theorin, A., Bengtsson, K., Provost, J., Lieder, M., Johnsson, C., Lundholm, T., \& Lennartson, B. (2017). An event-driven manufacturing information system architecture for Industry 4.0. International Journal of Production Research, 55(5), 1297-1311.

Tortorella, G. L., \& Fettermann, D. (2018). Implementation of Industry 4.0 and lean production in Brazilian manufacturing companies. International Journal of Production Research, 56(8), 2975-2987. 
Tu, M., Lim, M. K., \& Yang, M. F. (2018). IoT-based production logistics and supply chain system-Part 1: Modeling IoT-based manufacturing supply chain. Industrial Management \& Data Systems, 118(1), 65-95.

UN - United Nations, (2019). Sustainable Development Goals. Accessed May 2019, https://sustainabledevelopment.un.org/sdgs

Varela, L., Araújo, A., Ávila, P., Castro, H., \& Putnik, G. (2019). Evaluation of the Relation between Lean Manufacturing, Industry 4.0, and Sustainability. Sustainability, 11(5), 1439.

Venables, M. (2016), Are we there yet?: Technologies such as the industrial internet of things, smart manufacturing and industry 4.0 digitisation are supposed to be ushering in a new age of innovation. do they justify the hype? Plant Engineer, 2016-March(March-April), 28-30.

Vujosevic, R. (1994). Visual interactive simulation and artificial intelligence in design of flexible manufacturing systems. International Journal of Production Research, 32(8), 1955-1971.

Wang, L., \& Wang, X. V. (2018). Outlook of Cloud, CPS and IoT in Manufacturing. In CloudBased Cyber-Physical Systems in Manufacturing (pp. 377-398). Springer, Cham.

Wang, Y., Lin, Y., Zhong, R. Y., \& Xu, X. (2018). IoT-enabled cloud-based additive manufacturing platform to support rapid product development. International Journal of Production Research, 1-17.

Wang, L., \& Wang, G. (2016). Big data in cyber-physical systems, digital manufacturing and industry 4.0. International Journal of Engineering and Manufacturing (IJEM), 6(4), 1-8.

Wang, L., Törngren, M., \& Onori, M. (2015). Current status and advancement of cyber-physical systems in manufacturing. Journal of Manufacturing Systems, 37, 517-527.

Webster, J., \& Watson, R. T. (2002). Analysing the past to prepare for the future. MIS Quarterly, 26(2), 49.

WEF. World Economic Forum, (2018). AI and robots could create as many jobs as they displace, Accessed May 2019. https://www.weforum.org/agenda/2018/09/ai-and-robots-could-createas-many-jobs-as-they-displace/

WIPO, (2018). World Intellectual Property Indicators. Accessed in May 2019. https://www.wipo.int/publications/en/details.jsp?id=4369

Yadegaridehkordi, E., Hourmand, M., Nilashi, M., Shuib, L., Ahani, A., \& Ibrahim, O. (2018). Influence of big data adoption on manufacturing companies' performance: An integrated DEMATEL-ANFIS approach. Technological Forecasting and Social Change, 137, 199-210.

Yao, X., Zhou, J., Zhang, J., \& Boër, C. R. (2017, September). From intelligent manufacturing to smart manufacturing for Industry 4.0 driven by next generation artificial intelligence and further On. In 2017 5th International Conference on Enterprise Systems (ES) (pp. 311-318). IEEE.

Yang, J., Chen, Y., Huang, W., \& Li, Y. (2017, September). Survey on artificial intelligence for additive manufacturing. In 2017 23rd International Conference on Automation and Computing (ICAC) (pp. 1-6). IEEE. 
Zaki, M., Theodoulidis, B., Shapira, P., Neely, A., \& Tepel, M. F. (2017). Redistributed Manufacturing and the Impact of Big Data: A Consumer Goods Perspective.

Zhang, Y., Ma, S., Yang, H., Lv, J., \& Liu, Y. (2018). A big data driven analytical framework for energy-intensive manufacturing industries. Journal of Cleaner Production, 197, 57-72.

Zheng, P., Sang, Z., Zhong, R. Y., Liu, Y., Liu, C., Mubarok, K., .. \& Xu, X. (2018). Smart manufacturing systems for Industry 4.0: Conceptual framework, scenarios, and future perspectives. Frontiers of Mechanical Engineering, 13(2), 137-150.

Zheng, Y., Wu, W., Chen, Y., Qu, H., \& Ni, L. M. (2016). Visual analytics in urban computing: An overview. IEEE Transactions on Big Data, 2(3), 276-296. doi:10.1109/TBDATA.2016.2586447

Zhong, R. Y., Xu, X., Klotz, E., \& Newman, S. T. (2017a). Intelligent manufacturing in the context of industry 4.0: a review. Engineering, 3(5), 616-630.

Zhong, R. Y., Xu, C., Chen, C., \& Huang, G. Q. (2017b). Big data analytics for physical internetbased intelligent manufacturing shop floors. International journal of production research, 55(9), 2610-2621.

Zhou, K., Fu, C., \& Yang, S. (2016). Big data driven smart energy management: From big data to big insights. Renewable and Sustainable Energy Reviews, 56, 215-225.

Zhou, K., Liu, T., \& Zhou, L. (2015, August). Industry 4.0: Towards future industrial opportunities and challenges. In 2015 12th International Conference on Fuzzy Systems and Knowledge Discovery (FSKD) (pp. 2147-2152). IEEE.

Zúñiga, E., Syberfeldt, A., \& Urenda Moris, M. (2017). The Internet of Things, Factory of Things and Industry 4.0 in Manufacturing: Current and Future Implementations. In 15th International Conference on Manufacturing Research ICMR 2017. Incorporating the 32nd National Conference on Manufacturing Research. University of Greenwich, London, September 5-7, 2017 (pp. 221-226). IOS Press. 